\title{
$\$$ Research Square

\section{Characterization of Thrust Force, Temperature, Chip Morphology and Power in Ultrasonic-assisted Drilling of Aluminium 6061}

\section{Amin Moghaddas ( $\sim$ moghaddas.6@osu.edu )}

Edison Welding Institute

\section{Research Article}

Keywords: Response surface methodology, Ultrasonic-assisted drilling, Thrust force, Temperature, Chip Morphology, Mathematical model, Aluminum 6061, Optimization

Posted Date: April 23rd, 2021

DOI: https://doi.org/10.21203/rs.3.rs-441144/v1

License: (1) (1) This work is licensed under a Creative Commons Attribution 4.0 International License. Read Full License

Version of Record: A version of this preprint was published at The International Journal of Advanced Manufacturing Technology on September 12th, 2021. See the published version at https://doi.org/10.1007/s00170-021-07742-8. 
Characterization of Thrust Force, Temperature, Chip Morphology and Power in Ultrasonic-assisted Drilling of Aluminium 6061

Amin Moghaddas

M. A. Moghaddas, amoghaddas@ewi.org

Edison Welding Institute, Columbus, Ohio 43221, USA 


\begin{abstract}
In this study, a special resolution V design and Response surface methodology (RSM) were used to characterize the ultrasonic-assisted drilling (UAD) process of Aluminum 6061. This characterization was done through developing mathematical models to study the effect of ultrasonic and drilling parameters including spindle speed, feed rate and amplitude on thrust force, temperature, chip morphology and power. The tests were done using an industrially hardened non-rotating UAD system mounted in a CNC turning center. The analysis of variance (ANOVA) was used to find significant parameters of thrust force, temperature, chip morphology and power. Then, for all responses, the optimum drilling parameters that provide desired solutions for all responses were obtained. This was followed by out-of-sample testing to verify the accuracy of the developed models. The results of this study showed that in UAD of aluminum, the minimum values of thrust force and chip size were obtained at low spindle speed, low feed rate and high amplitude. The results also showed that amplitude was not a significant parameter affecting the tool temperature and cannot be used to analyze the effect of ultrasonic vibrations on generated heat during UAD. Instead, the interaction of amplitude and feed rate was significant and should be considered in the analysis. Finally, minimum consumed power, specially at higher amplitudes, can be obtained using high spindle speed and low feed rate.
\end{abstract}

Keywords

Response surface methodology; Ultrasonic-assisted drilling; Thrust force; Temperature; Chip Morphology; Mathematical model; Aluminum 6061; Optimization

\title{
Introduction
}

Due to the strength-to-weight ratio as well as corrosion resistance of aluminum alloys, these alloys are widely used in various industries such as aircraft, aerospace, and automotive. Of the several conventional processes used to machine this material, conventional drilling (CD) ranks as one of the most demanding machining processes. While aluminum alloys have been considered as one of the easy-to-machine materials, drilling this material has some limitations including low surface roughness of the drilled holes, built-up edge (BUE), and exit burr. Recently a promising technique known as ultrasonic-assisted drilling (UAD) has attracted much attention because it can overcome the technological constraints just mentioned. The UAD process is a technology 
that applies high frequency vibrations $(>20 \mathrm{kHz})$ at amplitudes of $2-20 \mu \mathrm{m}$ in the feed direction to either the drill tip or work piece to improve drilling conditions and productivity. It should be noted that UAD is distinct from ultrasonic drilling (UD), which is also known as rotary ultrasonic machining, where it uses an abrasive slurry to remove material from a workpiece.

While there is uncertainty as to the first application of ultrasonics to the drilling process, the work of Onikura et al. (1966) could be considered as one of the first applications of ultrasonic vibrations to drilling. They conducted an experimental study using a $40-\mathrm{kHz}$ UAD system to investigate the effects of ultrasonic vibrations on thrust force, torque, and dimensional accuracy of drilling age-hardenable aluminum alloy (Duralumin) with 1-mm drills. The spindle speed range and feed rate used in this study were 1000-3000 RPM and 5-10 $\mu \mathrm{m} / \mathrm{rev}$, respectively. The results of this study showcased that ultrasonic vibrations reduced thrust force and torque by $50 \%$ and $80 \%$, respectively. The study also demonstrated improved hole oversize and significant displacement of the hole's center, while no improvement was observed on hole roundness. The results highlighted that applying ultrasonic vibrations reduced the chip thickness by more than $30 \%$ and the chip thickness reduction takes place more often at lower rotational speed and feed rate. The work of Takeyama and Kato (1991) is another early work in the UAD of aluminum where the thrust force and burr height in drilling pure aluminum with four different custom drills were studied. In this study, the ultrasonic vibrations were applied to the workpiece via a transducer that was attached to the table of a milling machine. The thrust force was measured at two different feed rates $(0.08$ and $0.15 \mathrm{~mm} / \mathrm{rev})$ and constant spindle speed (115 RPM) and showed that at the highest amplitude $(13.5 \mu \mathrm{m})$, more force reduction, less material deterioration, and less burr height can be obtained.

In recent years, UAD of aluminum has been the subject of extensive research because of its benefits such as lower thrust force, lower torque, improvement of drill life, less burr height, smaller chips, improvement in dimensional accuracy, and improvement in surface roughness. Ma et al. (2005) developed a system assisted by ultrasonic elliptical vibration (UEV). This system that tuned at $18.87 \mathrm{kHz}$ can apply circular vibrations with a $2-\mu \mathrm{m}$ radius to the workpiece. Their experimental drilling tests on aluminum (52S) with a $0.65-\mathrm{mm}$ carbide drill at 100 RPM demonstrated that UEV can reduce the axial and radial drilling forces up to $33 \%$ and $50 \%$, respectively, compared to axial and radial forces experienced in CD. They also measured the chip thickness in UEV and found that applying an elliptical vibration can reduce the chip thickness in UEV up to $50 \%$ compared to CD. 
Neugebauer and Stoll (2004) investigated the evaluation of the influence of ultrasonic vibrations on cutting force, cutting moment, and chip breakage when drilling an aluminum alloy with 6-mm coated and uncoated carbide twist drills. They discovered that the application of ultrasonic vibrations in the drilling process can possibly reduce force and torque by up to $50 \%$. They provided illustrations that show the effect of vibration on chip size compared to CD; however, the authors have not discussed the setup they used to apply ultrasonic vibrations to the drilling process.

Li et al. (2016) used a 30-kHz UAD system to study the effect of machining parameters on thrust force of the cutting lips and chisel edge in $\mathrm{CD}$ and UAD, separately. They pre-drilled pilot holes in a 12-mm thick aluminum 7075 to eliminate the thrust force of the chisel edge and their results showed the feed rate would affect thrust force of the chisel edge more than the thrust force of the cutting lips. However, increasing spindle speed increased the thrust force of the cutting lips and had little influence on the thrust force of the chisel edge.

Chu et al. (2020) used a transducer that was held in the three-jaw chuck of a lathe to study torque in $\mathrm{CD}$ and $\mathrm{UAD}$ of aluminum 6061 with high depth to dimeter ratio (e.g., 13.3) by studying the components of torque which are cutting torque, rubbing torque and stick-slip torque. The results of their study showed that the reductions of both rubbing torque and stick-slip torque would be main reasons for the enhancement of machinability in deep drilling of UAD over CD. In the work of Wei and Wang (2019), finite element analysis (FEA) was used to evaluate the effect of machining and ultrasonic parameters in drilling of Ti6Al4V/Al2024-T351. The results of this study showed that while UAD can produce smaller chips, lower thrust force, and lower effective stress, the maximum temperature in UAD of aluminum layer was increased by $10.3 \%$ compared to CD. Similar FEA using Deform-3D was done by Wei and Wang (2020) on Ti6A14V/A12024-T351. Using two different drill bits similar results were obtained, except temperature was lower in $\mathrm{UAD}$ when compared to $\mathrm{CD}$.

While the extensive record of past research on UAD of aluminum has provided valuable data, few parametric studies were conducted and reported to find critical parameters influencing UAD performance and characterizing, modeling, and optimizing of UAD of aluminum. The laboratory nature of the existing systems limits their application for industrial production. Most studies considered dry drilling and were restricted to small drill sizes, and RPM and feed rate levels were well below typical production conditions. Moreover, there is a lack of agreement 
among researchers on the effect of machining and vibration parameters on generated heat in UAD.

Moghaddas et al. (2018a) in their earlier experimental investigations developed a robust UAD system and used that to investigate several benefits of UAD Aluminum 6061 including thrust force and torque reduction. In another work, Moghaddas et al. (2018b) used the developed UAD system and showed improvement in productivity and surface roughness in UAD of Aluminum 6061, Stainless steel 316 and Titanium. Moghaddas et al. (2019) evaluated several temperature measurement techniques in UAD and used the best technique to study the effects of vibration amplitude on thrust force and heat generation for different materials.

The present work intends to characterize the UAD Aluminum 6061 using an industrially hardened UAD system mounted in a MAZAK CNC turning center. Response surface methodology is used to develop mathematical models to study the effects of the drilling parameters such as spindle speed, feed rate, and vibration amplitude on thrust force, temperature, chip morphology and power as well as to find the optimum drilling parameters that provide desired solutions.

\section{Methodology}

The methodology used in this work to create experimental design and to analyze the data was elaborated in detail in (Moghaddas 2020). Design of Experiment (DOE) was used to efficiently plan the experiments using a special resolution V design (Diamond 1981) and a 28-trial experimental plan with three 4-level variables was created. The experiments were performed based on the DOE using a wide range of drilling parameters to provide multi-dimensional combinations and assurance of results quality. Then, statistical analysis of the responses (e.g., temperature) was performed by analysis of variance (ANOVA) to study the contribution of the variables and their interactions. Finding the significant variables and the effects of each variable on the responses was the main part of this analysis. RSM, which is a tool to predict the causeand-effect relationship between responses and input factors, was used to analyze the UAD data, provide mathematical models and find the optimum solutions. To create the mathematical models, the second order non-linear mathematical models with linear, quadratic, and interactive terms shown in Equation 1 were obtained with a 5\% level of significance. 


$$
Y=\text { Contant }+a_{1} A+b_{1} N+c_{1} F+d_{1} A^{2}+e_{1} N^{2}+f_{1} F^{2}+g_{1} A N+h_{1} A F+i_{1} N F
$$

where $Y$ is the response, $A$ is amplitude, $N$ is spindle speed, $F$ is feed rate and $a_{1}, \ldots, i_{1}$ are the obtained regression coefficients using Minitab software. The results are represented graphically, by providing the main effect plots, interaction plots, and contour plots to visualize the effects of the drilling parameters on each response. Finally, out-of-sample testing was used to check the accuracy of the developed mathematical models.

\section{Equipment and Test Procedure}

The drilling trials were conducted using the setup shown in Figure 1, using a 2.5-kW nonrotating compression collet module mounted in a MAZAK CNC turning center.

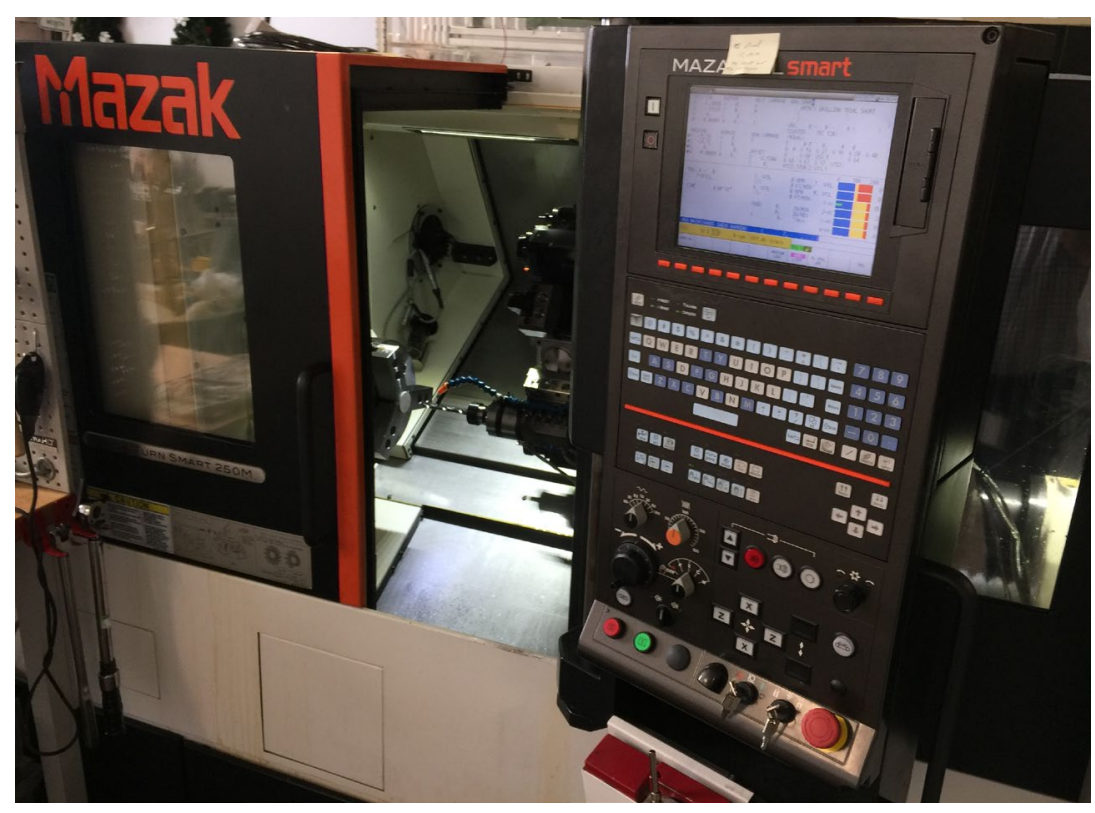

Figure 1. Experimental Setup

A $12.5-\mathrm{mm}$ drill, with 114-mm stick-out, was used to tune the module, with the resulting anti-resonant frequencies of $19.86 \mathrm{kHz}$ (Point 2 in Figure 2), which was measured with the Hewlett Packard HP429A impedance analyzer (Figure 3). As shown in Figure 2, no parasitic mode can be seen in the frequency range of the power supply (i.e., 19-21 kHz). To ensure the consistency of the module's anti-resonant frequency, the same drill stick-out was used for all the tests when new drills were used. To provide a consistent coupling between the collet and the drill 
during the tests, a torque wrench was used to apply $170 \mathrm{~N} \cdot \mathrm{m}$ to the collet nut of the modules after inserting each new drill.

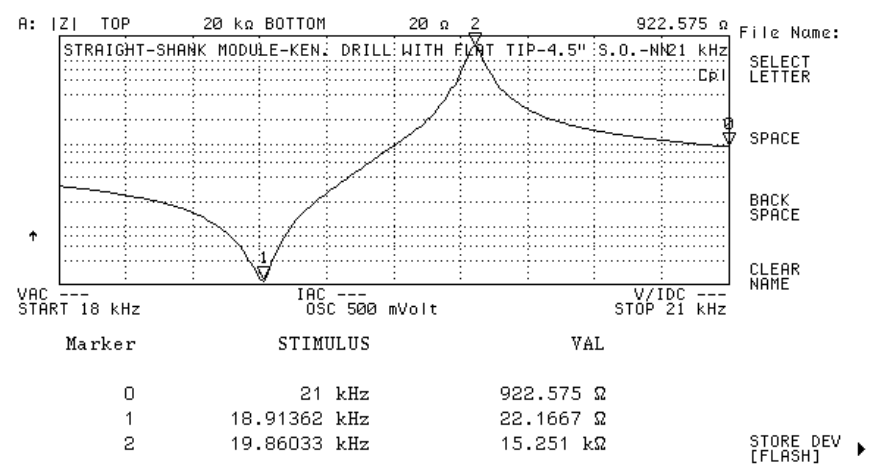

Figure 2. Impedance Curve of the Non-Rotating Compression Collet Module

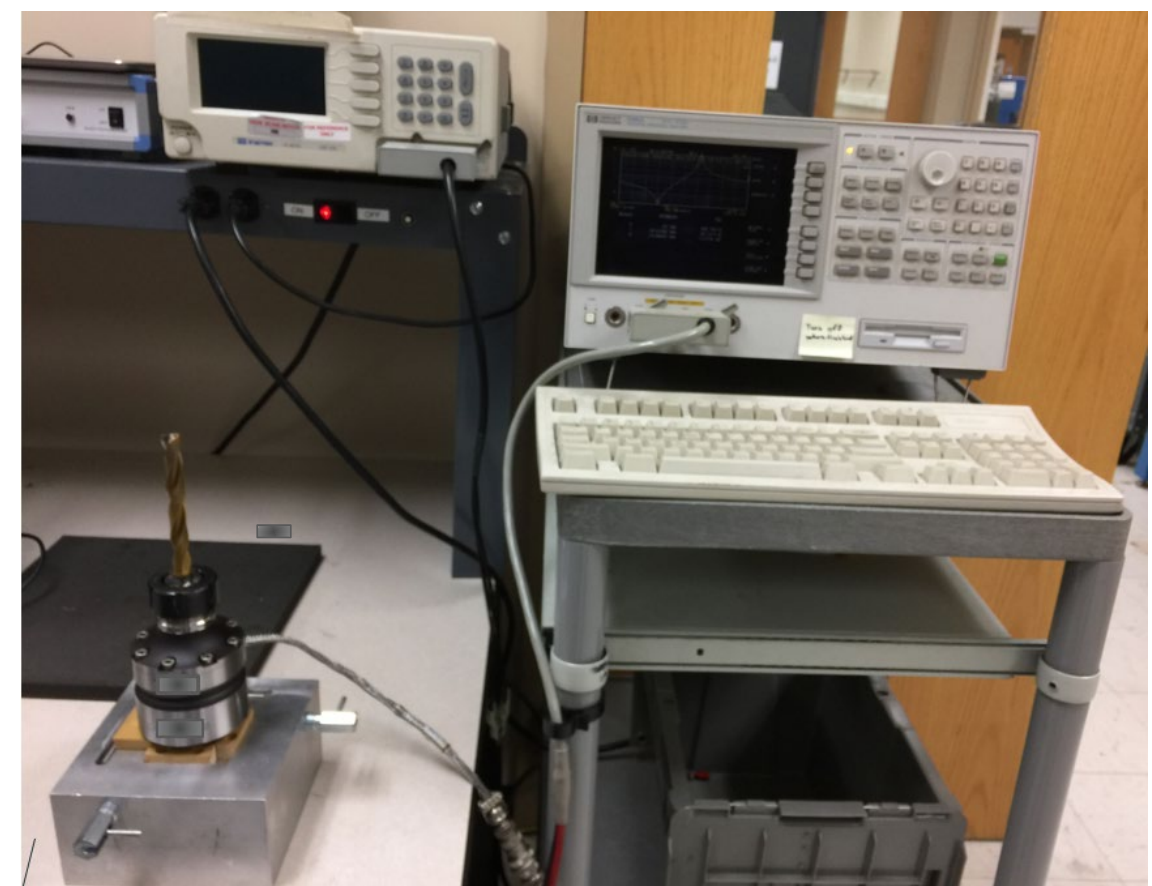

Figure 3. Hewlett Packard Impedance Analyzer to Determine the Anti-Resonant Frequency of the UAD System

Once tuned, the module was characterized using a Polytec laser vibrometer (HSV2000) to measure the ultrasonic amplitude present at the module drill tip in microns (Figure 4). The measurement of amplitude, when the module is at a stationary position and under load, is 
described in Moghaddas and Graff (2020). In this study, the amplitude measurement was performed when the module was in a stationary position.
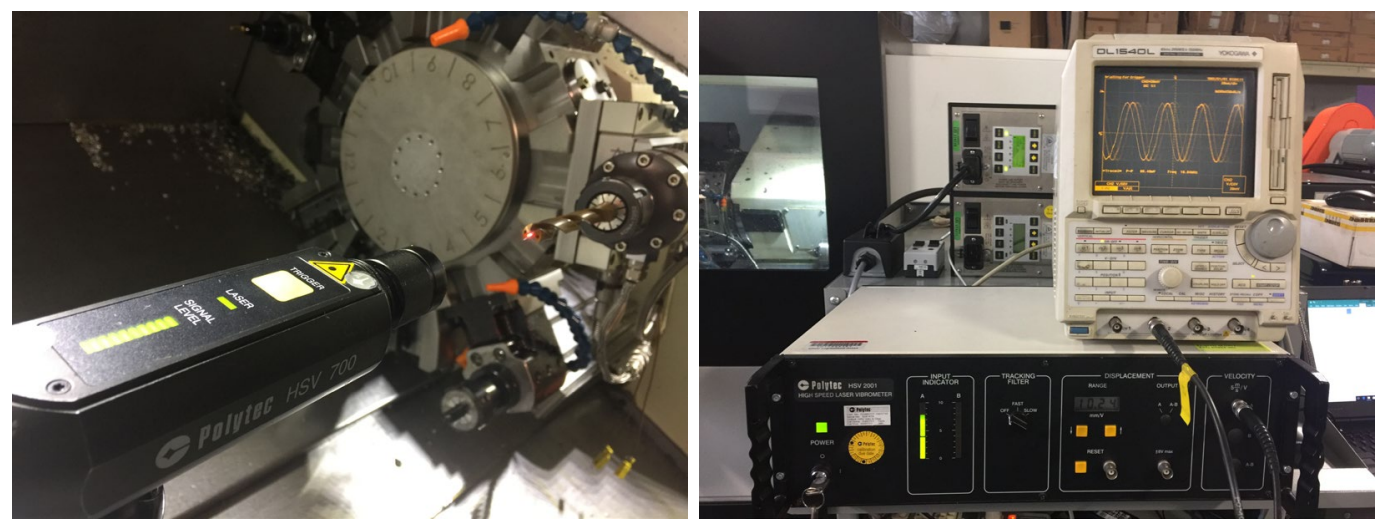

Figure 4. Setup for Amplitude Measurement on the Drill Tip

Table 1 shows the peak-to-peak amplitude that corresponds to different power supply amplitude settings for the drill tip.

Table 1. Peak-to-peak Amplitude at Different Drill Tip Amplitude Settings

\begin{tabular}{cccccc}
\hline $\begin{array}{c}\text { Trial } \\
\text { No. }\end{array}$ & $\begin{array}{c}\text { Amplitude } \\
(\%)\end{array}$ & $\begin{array}{c}\text { Amplitude } \\
(\mu \mathrm{m})\end{array}$ & $\begin{array}{c}\text { Velocity } \\
(\mathrm{mv})\end{array}$ & $\begin{array}{c}\text { Power } \\
(\text { Watts })\end{array}$ & $\begin{array}{c}\text { Frequency } \\
(\mathrm{Hz})\end{array}$ \\
\hline 1 & 20 & 3.38 & 85 & 3 & 19,819 \\
2 & 25 & 4.14 & 104 & 5 & 19,794 \\
3 & 30 & 4.98 & 125 & 8 & 19,785 \\
4 & 35 & 5.77 & 145 & 11 & 19,776 \\
5 & 40 & 6.61 & 166 & 13 & 19,770 \\
6 & 45 & 7.40 & 186 & 16 & 19,761 \\
7 & 50 & 8.20 & 206 & 19 & 19,757 \\
8 & 55 & 9.00 & 226 & 23 & 19,746 \\
9 & 60 & 9.87 & 248 & 25 & 19,739 \\
10 & 65 & 10.67 & 268 & 29 & 19,730 \\
11 & 70 & 11.46 & 288 & 33 & 19,721 \\
12 & 75 & 12.34 & 310 & 38 & 19,714 \\
13 & 80 & 13.14 & 330 & 44 & 19,708 \\
14 & 85 & 14.01 & 352 & 50 & 19,700 \\
15 & 90 & 14.81 & 372 & 58 & 19,692 \\
16 & 95 & 15.68 & 394 & 69 & 19,680 \\
17 & 100 & 17.04 & 428 & 78 & 19,668 \\
\hline
\end{tabular}

The alignment of the module with the center of the machine's spindle was checked with the setup shown in Figure 5. 


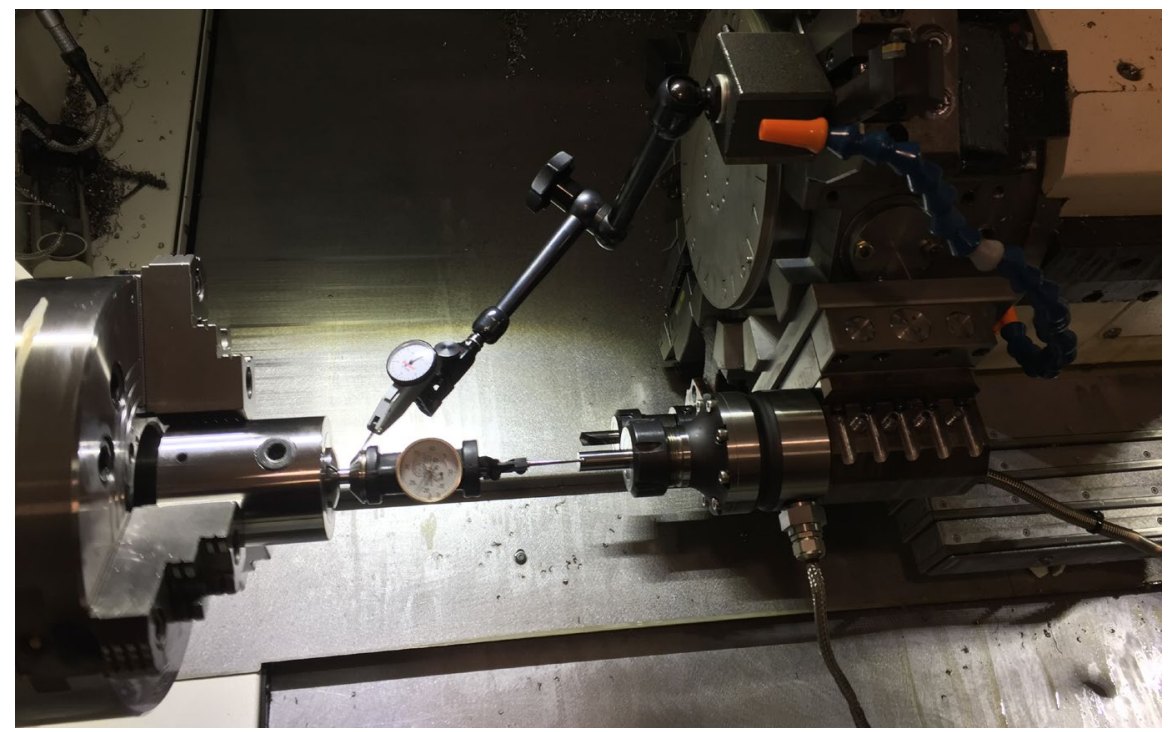

Figure 5. Setup for Aligning the Module with the Center of the Machine's Spindle

The instrumentation used in Figure 5 was a $0.0025-\mathrm{mm}$ dial indicator and a co-axial indicator. The dial indicator was used to center the co-axial indicator to within $0.0025-0.0050$ $\mathrm{mm}$. This was to ensure that the co-axial indicator is properly centered in the spindle. Then the co-axial indicator was used to center the module in to less than $0.012 \mathrm{~mm}$ using a ground carbide rod that is extending approximately $30 \mathrm{~mm}$ out from the face of the collet nut.

When the module aligned with the center of the machine's spindle, a 12.5-mm drill with 114-mm stick-out was inserted into the module and the module was powered using a Dukane 20$\mathrm{kHz}, 2.5-\mathrm{kW}$ power supply.

The material tested in this study was Aluminum 6061 in the form of a 12.7-mm thick, 44.45-mm diameter puck and was clamped in the machine's jaws, with 400-psi pressure. Kennametal solid carbide drills (B286D12500HPS) designed for aluminum drilling, were used for these tests and Blasocut 2000-series water-based coolant was applied to cool both the drill and the workpiece in the flood arrangement. To ensure the oil percentage of this coolant was within the recommended coolant manufacturer (i.e., 8-12\%), a refractometer was used to check it before and during the drilling trials.

To monitor the effect of drill wear on thrust force, baseline parameters were defined for drilling aluminum. These parameters were used to drill the aluminum and the thrust force was measured when the first hole was drilled. After drilling ten holes, another hole was drilled with the baseline parameters and the thrust force was measured and compared with the results obtained from drilling the first hole. If the measured thrust force was increased by more than 5\% 
during the drilling tests, a new drill was used, otherwise the same drill was used for the remainder of the tests.

In this study, spindle speed, feed rate, and amplitude are the variables. Kennametal machining handbook (Kennametal 2013) was used to determine the range of these variables. To evaluate the performance of the drill under the obtained range, a parameter development was conducted to evaluate the maximum and minimum values of spindle speed, feed rate, and amplitude that could be handled by the drill. It should be noted that the drill did not experience any premature failure or chipping in that evaluation. When the maximum and minimum values of each drilling parameters were established, four values were assigned to these ranges. These values are summarized in Table 2.

Table 2. The Levels of Drilling Parameters used in the DOE

\begin{tabular}{ccccc}
\hline Drilling Parameter & Level 1 & Level 2 & Level 3 & Level 4 \\
\hline Spindle Speed (RPM) & 1479 & 2312 & 3145 & 3978 \\
Feed Rate (IPR) & 0.01 & 0.014 & 0.018 & 0.022 \\
Amplitude $(\mu \mathrm{m})$ & 4 & 7 & 10 & 13 \\
\hline
\end{tabular}

Based on the special resolution V design discussed in Moghaddas (2020), a 28-trial experiment with three 4-level variables was created and the settings that were used for each trial are provided in Table 3. Note that each test, in Table 3, was repeated two times and the average value of the two tests was used for the data analysis.

Table 3. Experimental Design for Scenario 2

\begin{tabular}{cccc}
\hline $\begin{array}{c}\text { Test } \\
\text { No. }\end{array}$ & $\begin{array}{c}\text { Spindle Speed } \\
(\text { RPM })\end{array}$ & $\begin{array}{c}\text { Feed Rate } \\
(\text { IPR })\end{array}$ & $\begin{array}{c}\text { Amplitude } \\
(\mu \mathrm{m})\end{array}$ \\
\hline 1 & 1479 & 0.01 & 4 \\
2 & 3978 & 0.01 & 4 \\
3 & 3145 & 0.018 & 4 \\
4 & 2312 & 0.018 & 4 \\
5 & 3145 & 0.014 & 4 \\
6 & 2312 & 0.014 & 4 \\
7 & 1479 & 0.022 & 4
\end{tabular}




\begin{tabular}{cccc}
\hline $\begin{array}{c}\text { Test } \\
\text { No. }\end{array}$ & $\begin{array}{c}\text { Spindle Speed } \\
(\text { RPM })\end{array}$ & $\begin{array}{c}\text { Feed Rate } \\
(\text { IPR })\end{array}$ & $\begin{array}{c}\text { Amplitude } \\
(\mu \mathrm{m})\end{array}$ \\
\hline 8 & 3978 & 0.022 & 4 \\
9 & 3145 & 0.01 & 10 \\
10 & 2312 & 0.01 & 10 \\
11 & 1479 & 0.018 & 10 \\
12 & 3978 & 0.018 & 10 \\
13 & 1479 & 0.014 & 10 \\
14 & 3978 & 0.014 & 10 \\
15 & 3145 & 0.022 & 10 \\
16 & 2312 & 0.022 & 10 \\
17 & 3145 & 0.01 & 13 \\
18 & 3978 & 0.018 & 7 \\
19 & 3978 & 0.022 & 13 \\
20 & 2312 & 0.022 & 4 \\
21 & 3145 & 0.022 & 4 \\
22 & 2312 & 0.014 & 7 \\
23 & 3145 & 0.018 & 10 \\
24 & 2312 & 0.018 & 10 \\
25 & 1479 & 0.022 & 13 \\
26 & 3145 & 0.014 & 7 \\
27 & 2312 & 0.01 & 13 \\
28 & 1479 & 0.018 & 7 \\
\hline
\end{tabular}

The results investigated in this study included thrust force, drill temperature, chip morphology, and the power consumed during the process. To measure thrust force, a threecomponent Kistler dynamometer (Model \#: 9129A) was used.

To measure temperature during the drilling process, two K-type thermocouples (GG-K30-SLE-100) were inserted into the cooling channels of the drill and a high temperature epoxy was used to fill the cooling channel (Figure 6). The description of the equipment, as well as the installation process, are explained in Moghaddas et al. 2019. 


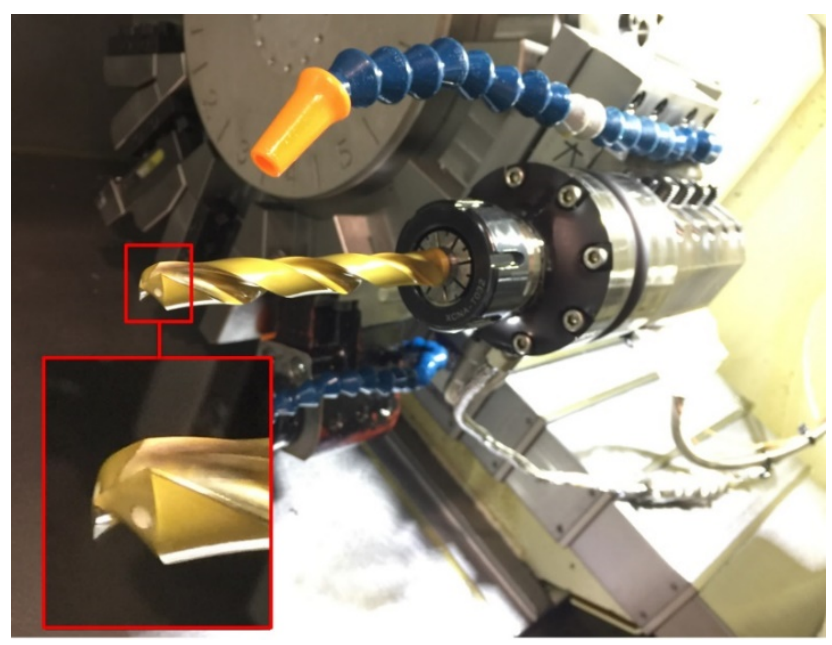

Figure 6. Thermocouples Inserted into the Cooling Channels of the Drill, then Covered with High Temperature Epoxy

To study the effect of the drilling parameters on the chip formation, an index was defined in this study and named "chips segmentation index." This index is the ratio of the quantity of the chips generated at each test to the weight of the chips (Equation 2).

$$
C S_{i}=\frac{Q_{i}}{W_{i}}
$$

where $C S_{i}$ is chips segmentation index, $Q_{i}$ is the quantity of the chips, and $W_{i}$ is the weight of the chips.

The amount of average value of consumed power during the UAD process was also captured and used in the data analysis. A representation of power data obtained is shown in Figure 7.

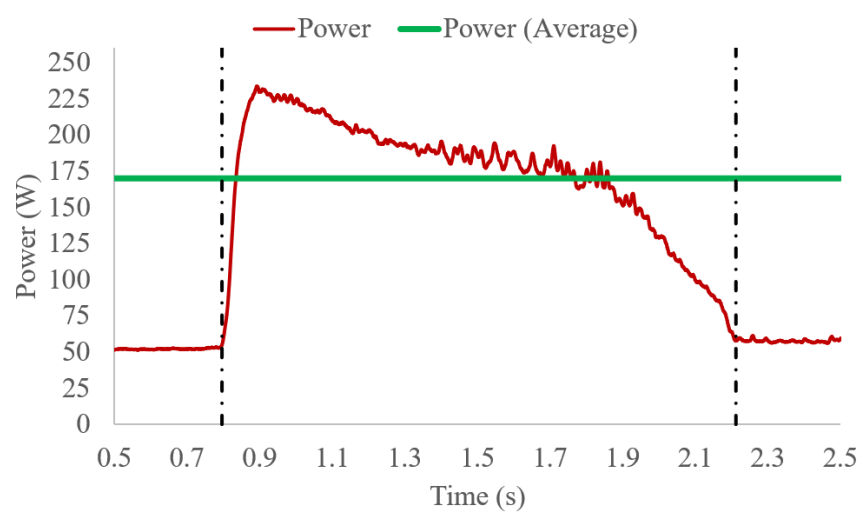

Figure 7. Representative data for the power consumed by the module during the UAD of Aluminum 6061, with 1,479 RPM, 0.014 IPR, and 10- $\mu$ m amplitude 
As seen in Figure 7, the maximum power (i.e., 232 Watts) occurred when the drill was engaged with material after 0.9 seconds and started decreasing near the end of the drilling process. The average value of consumed power (i.e., green line) considered for data analysis (i.e., $170 \mathrm{~W}$ ) was calculated by averaging the power data captured from the beginning of the drilling process (i.e., left vertical black line) until the end of the drilling process (i.e., right vertical black line).

\section{Results and Discussion}

Minitab was used for the data analysis provided in this work. As mentioned earlier, RSM was used to analyze the UAD data, and a stepwise regression method was used to fit the regression models. The validity of the regressions was examined using three criteria: ANOVA, coefficient of determination $\left(\mathrm{R}^{2}\right)$, and residual plots. In addition, the main effect plots and the response surface plots were provided for each response and the optimum value of the drilling parameters for each response was determined. Finally, the testing data were used to verify the accuracy of the proposed models.

A summary of the results obtained in the UAD of Aluminum 6061 is provided in Table 4.

Table 4. Results Summary of the UAD Tests

\begin{tabular}{|l|c|c|c|c|c|c|c|}
\hline $\begin{array}{l}\text { Test } \\
\text { No. }\end{array}$ & $\begin{array}{c}\text { Spindle } \\
\text { speed } \\
(\mathrm{RPM})\end{array}$ & $\begin{array}{c}\text { Feed rate } \\
(\mathrm{IPR})\end{array}$ & $\begin{array}{c}\text { Amplitude } \\
(\mu \mathrm{m})\end{array}$ & $\begin{array}{c}\text { Thrust } \\
\text { Force } \\
(\mathrm{N})\end{array}$ & $\begin{array}{c}\text { Temperature } \\
\left({ }^{\circ} \mathrm{C}\right)\end{array}$ & $\begin{array}{c}\text { Chip } \\
\text { Segmentation } \\
(1 / \mathrm{g})\end{array}$ & $\begin{array}{c}\text { Power } \\
(\mathrm{W})\end{array}$ \\
\hline 1 & 1,479 & 0.01 & 4 & 867.5 & 79.5 & 8.78 & 22.5 \\
\hline 2 & 3,978 & 0.01 & 4 & 908 & 80 & 6.855 & 18.1 \\
\hline 3 & 3,145 & 0.018 & 4 & $1,531.5$ & 87 & 6.515 & 22.7 \\
\hline 4 & 2,312 & 0.018 & 4 & 1459 & 107 & 7.065 & 25.75 \\
\hline 5 & 3,145 & 0.014 & 4 & $1,203.5$ & 95 & 6.91 & 22.45 \\
\hline 6 & 2,312 & 0.014 & 4 & 1,189 & 100.5 & 7.635 & 22.4 \\
\hline 7 & 1,479 & 0.022 & 4 & $1,688.5$ & 104.5 & 7.17 & 27.5 \\
\hline 8 & 3,978 & 0.022 & 4 & 1,713 & 89 & 5.495 & 22.75 \\
\hline 9 & 3,145 & 0.01 & 10 & 686.5 & 98.5 & 8.32 & 130 \\
\hline 10 & 2,312 & 0.01 & 10 & 566 & 98 & 7.73 & 144.45 \\
\hline 11 & 1,479 & 0.018 & 10 & 980.5 & 103 & 7.36 & 172.4 \\
\hline 12 & 3,978 & 0.018 & 10 & 1,321 & 91.5 & 6.65 & 130.95 \\
\hline 13 & 1,479 & 0.014 & 10 & 666 & 98 & 8.425 & 169.9 \\
\hline 14 & 3,978 & 0.014 & 10 & 1,073 & 95.5 & 7.08 & 131.6 \\
\hline 15 & 3,145 & 0.022 & 10 & $1,568.5$ & 97.5 & 6.015 & 150.65 \\
\hline 16 & 2,312 & 0.022 & 10 & $1,456.5$ & 95.5 & 6.27 & 165.8 \\
\hline 17 & 3,145 & 0.01 & 13 & 548 & 99.5 & 8.83 & 237.1 \\
\hline 18 & 3,978 & 0.018 & 7 & $1,429.5$ & 92.5 & 6.28 & 67.2 \\
\hline & & & & & & & \\
\hline
\end{tabular}




\begin{tabular}{|l|c|c|c|c|c|c|c|}
\hline $\begin{array}{l}\text { Test } \\
\text { No. }\end{array}$ & $\begin{array}{c}\text { Spindle } \\
\text { speed } \\
(\mathrm{RPM})\end{array}$ & $\begin{array}{c}\text { Feed rate } \\
(\mathrm{IPR})\end{array}$ & $\begin{array}{c}\text { Amplitude } \\
(\mu \mathrm{m})\end{array}$ & $\begin{array}{c}\text { Thrust } \\
\text { Force } \\
(\mathrm{N})\end{array}$ & $\begin{array}{c}\text { Temperature } \\
\left({ }^{\circ} \mathrm{C}\right)\end{array}$ & $\begin{array}{c}\text { Chip } \\
\text { Segmentation } \\
(1 / \mathrm{g})\end{array}$ & $\begin{array}{c}\text { Power } \\
(\mathrm{W})\end{array}$ \\
\hline 19 & 3,978 & 0.022 & 13 & 1,467 & 87.5 & 5.52 & 245.95 \\
\hline 20 & 2,312 & 0.022 & 4 & $1,769.5$ & 102.5 & 6.42 & 28.6 \\
\hline 21 & 3,145 & 0.022 & 4 & 1,777 & 91.5 & 6.08 & 25.05 \\
\hline 22 & 2,312 & 0.014 & 7 & 1,052 & 97.5 & 7.985 & 72.9 \\
\hline 23 & 3,145 & 0.018 & 10 & 1,316 & 93 & 6.38 & 148.1 \\
\hline 24 & 2,312 & 0.018 & 10 & $1,138.5$ & 99.5 & 7.235 & 160.4 \\
\hline 25 & 1,479 & 0.022 & 13 & $1,024.5$ & 96 & 7.505 & 356.65 \\
\hline 26 & 3,145 & 0.014 & 7 & 1,109 & 94.5 & 7.185 & 69.95 \\
\hline 27 & 2,312 & 0.01 & 13 & 431 & 95 & 9.475 & 258.9 \\
\hline 28 & 1,479 & 0.018 & 7 & $1,240.5$ & 102 & 8.055 & 85.75 \\
\hline
\end{tabular}

Table 5, Table 6, Table 7, and Table 8 summarize the ANOVA of thrust force, temperature, chips segmentation and power models with $95 \%$ confidence level.

Table 5. ANOVA Results for Thrust Force

\begin{tabular}{ccccccc}
\hline Source & Term & DF & Adj SS & Adj MS & F-Value & P-Value \\
\hline Model & --- & 6 & 3663732 & 610622 & 819.78 & 0.000 \\
Linear & --- & 3 & 3423539 & 1141180 & 1532.07 & 0.000 \\
Amplitude & $\mathrm{A}$ & 1 & 595595 & 595595 & 799.61 & 0.000 \\
Spindle speed & $\mathrm{N}$ & 1 & 230306 & 230306 & 309.19 & 0.000 \\
Feed rate & $\mathrm{F}$ & 1 & 2332266 & 2332266 & 3131.15 & 0.000 \\
Square & --- & 2 & 21717 & 10859 & 14.58 & 0.000 \\
Amplitude $\times$ Amplitude & $\mathrm{A}^{2}$ & 1 & 4663 & 4663 & 6.26 & 0.023 \\
Spindle speed $\times$ Spindle & $\mathrm{N}^{2}$ & 1 & 17451 & 17451 & 23.43 & 0.000 \\
speed & & & & & & \\
2-Way Interaction & --- & 1 & 85325 & 85325 & 114.55 & 0.000 \\
Amplitude $\times$ Spindle speed & $\mathrm{A} \times \mathrm{N}$ & 1 & 85325 & 85325 & 114.55 & 0.000 \\
Error & --- & 17 & 12663 & 745 & --- & --- \\
Total & --- & 23 & 3676394 & --- & --- & -- \\
\hline
\end{tabular}


Table 6. ANOVA Results for Temperature

\begin{tabular}{ccccccc}
\hline Source & Term & DF & Adj SS & Adj MS & F-Value & P-Value \\
\hline Model & --- & 7 & 879.29 & 125.61 & 9.52 & 0.000 \\
Linear & --- & 3 & 223.42 & 74.47 & 5.65 & 0.008 \\
Amplitude & $\mathrm{A}$ & 1 & 36.37 & 36.37 & 2.76 & 0.116 \\
Spindle speed & $\mathrm{N}$ & 1 & 154.01 & 154.01 & 11.68 & 0.004 \\
Feed rate & $\mathrm{F}$ & 1 & 42.11 & 42.11 & 3.19 & 0.093 \\
Square & --- & 2 & 210.76 & 105.38 & 7.99 & 0.004 \\
Spindle speed $\times$ Spindle speed & $\mathrm{N}^{2}$ & 1 & 37.85 & 37.85 & 2.87 & 0.110 \\
Feed rate $\times$ Feed rate & $\mathrm{F}^{2}$ & 1 & 177.30 & 177.30 & 13.44 & 0.002 \\
2-Way Interaction & --- & 2 & 302.89 & 151.44 & 11.48 & 0.001 \\
Amplitude×Feed rate & $\mathrm{A} \times \mathrm{F}$ & 1 & 213.12 & 213.12 & 16.16 & 0.001 \\
Spindle speed $\times$ Feed rate & $\mathrm{N} \times \mathrm{F}$ & 1 & 95.63 & 95.63 & 7.25 & 0.016 \\
Error & --- & 16 & 211.04 & 13.19 & --- & --- \\
Total & --- & 23 & 1090.33 & --- & --- & --- \\
\hline
\end{tabular}

Table 7. ANOVA Results for Chips Segmentation

\begin{tabular}{ccccccc}
\hline Source & Term & DF & Adj SS & Adj MS & F-Value & P-Value \\
\hline Model & --- & 5 & 22.7997 & 4.5599 & 41.15 & 0.000 \\
Linear & --- & 3 & 22.6487 & 7.5496 & 68.12 & 0.000 \\
Amplitude & $\mathrm{A}$ & 1 & 1.2673 & 1.2673 & 11.44 & 0.003 \\
Spindle speed & $\mathrm{N}$ & 1 & 7.5912 & 7.5912 & 68.50 & 0.000 \\
Feed rate & $\mathrm{F}$ & 1 & 13.2642 & 13.2642 & 119.69 & 0.000 \\
Square & --- & 1 & 0.3048 & 0.3048 & 2.75 & 0.115 \\
Amplitude×Amplitude & $\mathrm{A}^{2}$ & 1 & 0.3048 & 0.3048 & 2.75 & 0.115 \\
2-Way Interaction & --- & 1 & 0.6478 & 0.6478 & 5.85 & 0.026 \\
Amplitude×Feed rate & $\mathrm{A} \times \mathrm{F}$ & 1 & 0.6478 & 0.6478 & 5.85 & 0.026 \\
Error & --- & 18 & 1.9948 & 0.1108 & --- & --- \\
Total & --- & 23 & 24.7945 & -- & --- & -- \\
\hline
\end{tabular}

Table 8. ANOVA Results for Power

\begin{tabular}{ccccccc}
\hline Source & Term & DF & Adj SS & Adj MS & F-Value & P-Value \\
\hline Model & --- & 6 & 194568 & 32428 & 478.04 & 0.000 \\
Linear & --- & 3 & 179165 & 59722 & 880.39 & 0.000 \\
Amplitude & A & 1 & 174689 & 174689 & 2575.18 & 0.000 \\
Spindle speed & $\mathrm{N}$ & 1 & 5089 & 5089 & 75.02 & 0.000 \\
Feed rate & $\mathrm{F}$ & 1 & 2031 & 2031 & 29.93 & 0.000 \\
Square & --- & 1 & 7778 & 7778 & 114.67 & 0.000 \\
Amplitude $\times$ Amplitude & $\mathrm{A} 2$ & 1 & 7778 & 7778 & 114.67 & 0.000 \\
2-Way Interaction & --- & 2 & 4503 & 2251 & 33.19 & 0.000 \\
Amplitude $\times$ Spindle speed & $\mathrm{A} \times \mathrm{N}$ & 1 & 3337 & 3337 & 49.19 & 0.000 \\
Amplitude $\times$ Feed rate & $\mathrm{A} \times \mathrm{F}$ & 1 & 1200 & 1200 & 17.68 & 0.001 \\
Error & --- & 17 & 1153 & 68 & -- & --- \\
Total & --- & 23 & 195721 & --- & -- & -- \\
\hline
\end{tabular}


In Table 5, Table 6, Table 7, and Table 8, DF is total degrees of freedom, Adj SS is adjusted sums of square, Adj MS is adjusted mean square, and F-Value is the test statistic used to determine whether the term is associated with the response. The probability value (i.e., P-value) is used in the testing of the hypothesis to help support or reject the null hypothesis. In this study, the significant terms of the models were determined by considering the terms that had a Pvalue equal or less than 0.05 .

Based on ANOVA results, the significant terms of thrust force, temperature, chips segmentation and power are identified (i.e., blue bars) and shown in the Pareto Chart depicted in Figure $8 \mathrm{a}, 8 \mathrm{~b}, 8 \mathrm{c}$, and $8 \mathrm{~d}$.
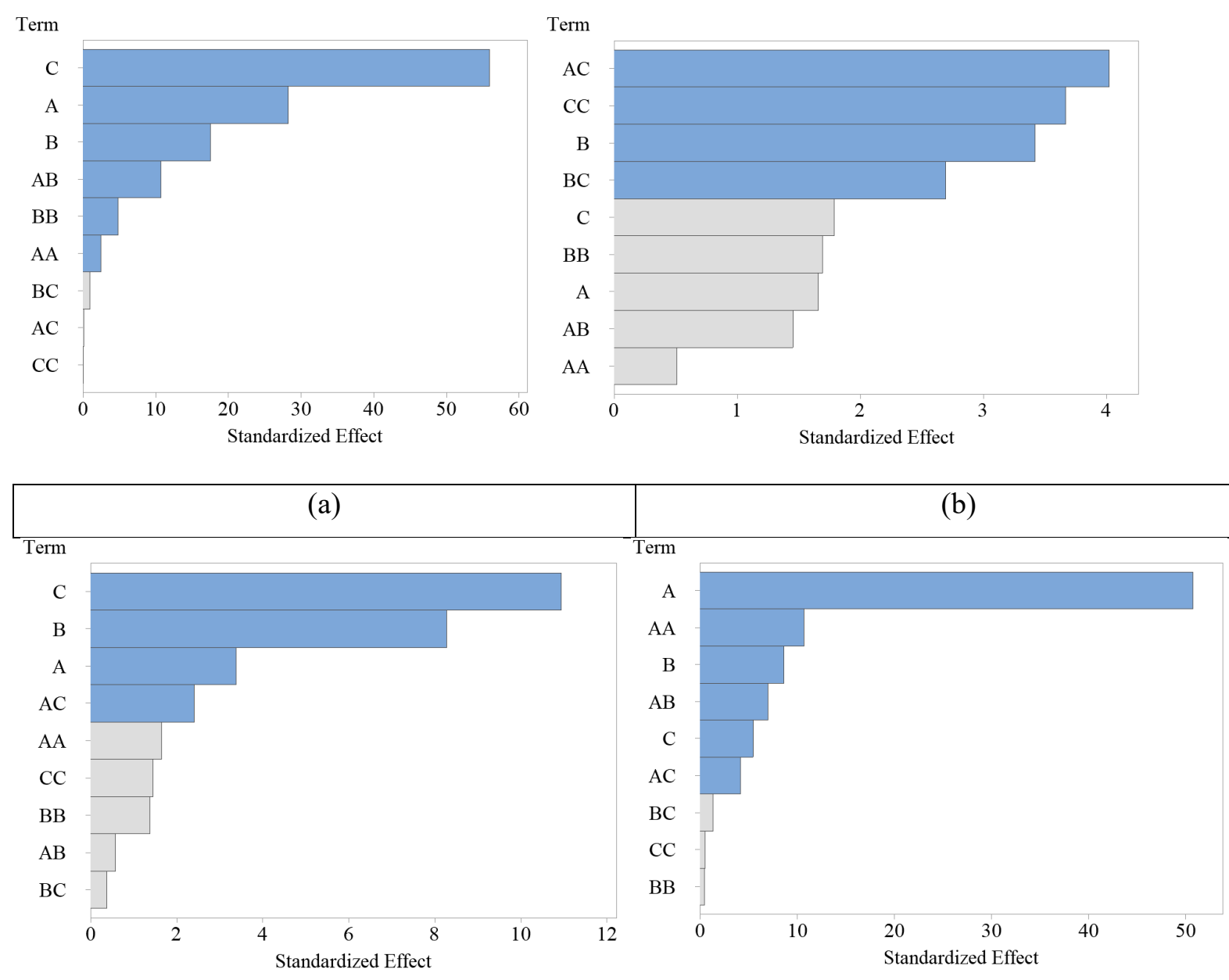

(c)

(d)

Figure 8. Pareto Chart of the Standardized Effects of a) Thrust force; b) Temperature; c) Chips segmentation; d) Power. Note: A, B and C are Amplitude, Spindle Speed and Feed Rate, Respectively. 
As seen in Figure 8a, feed rate had the most effect on thrust force, then amplitude, spindle speed, interaction of amplitude and spindle speed, squared spindle speed and squared amplitude are the significant terms affecting thrust force. These results are completely aligned with the results of thrust force analysis presented in Moghaddas 2020. For temperature (Figure $8 \mathrm{~b}$ ), interaction of amplitude and feed rate had the most effect, then squared feed rate, spindle speed, interaction of spindle speed and feed rate, are the significant terms, respectively. Similar to the results thrust force analysis, chips segmentation (Figure 8c) was affected more by feed rate. Then spindle speed, amplitude, and interaction of amplitude and feed rate had the most effect on chips segmentation, respectively. Finally, amplitude had the most effect on consumed power of power supply (Figure 8d). Next, squared amplitude, spindle speed, interaction of amplitude and spindle speed, feed rate, and interaction of amplitude and feed rate had the most effect on the consumed power, respectively.

Figure 9 shows the normal probability plots of the residuals for thrust force, temperature, chips segmentation and power.
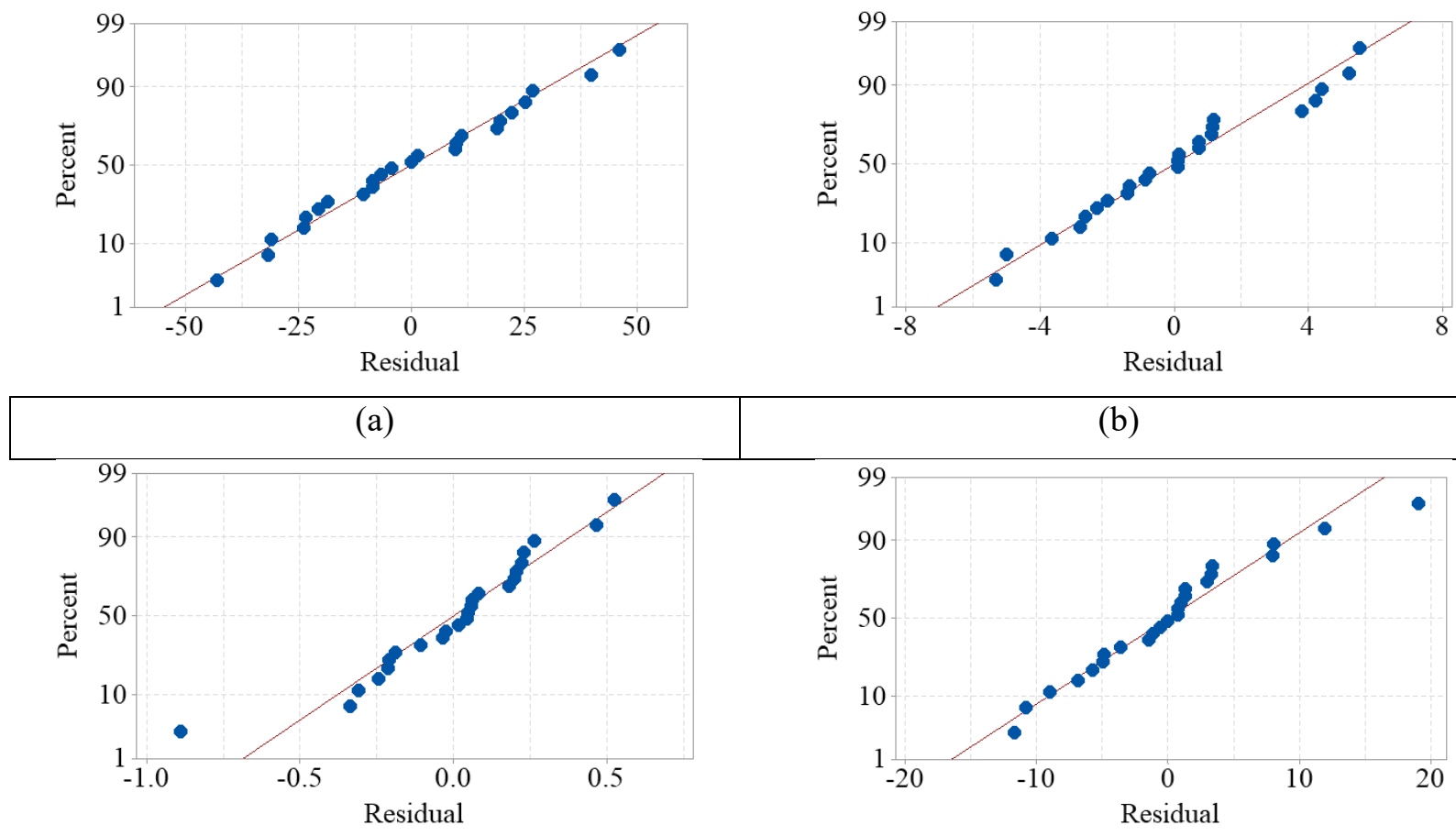

(c)

(b)

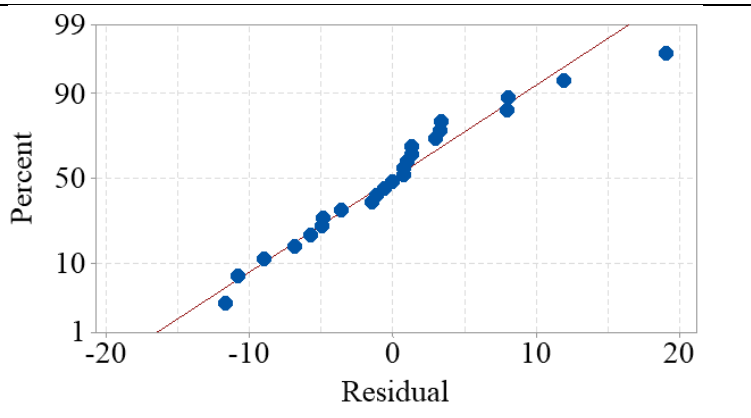

(d)

Figure 9. Residual Plots for a) Thrust Force; b) Temperature; and c) Chips segmentation; d) Power 
Residual plots reveal unwanted residual patterns and indicate biased results more effectively than numbers. It is essential that the residuals are normally distributed for the regression analysis to be valid. As shown in the upper graphs of Figure 9a, 9b, 9c, and 9d the closeness of residuals to the diagonal line represent an ideal normal distribution. This indicates that the residuals are normally distributed. The main effects plots are shown in Figure 10.
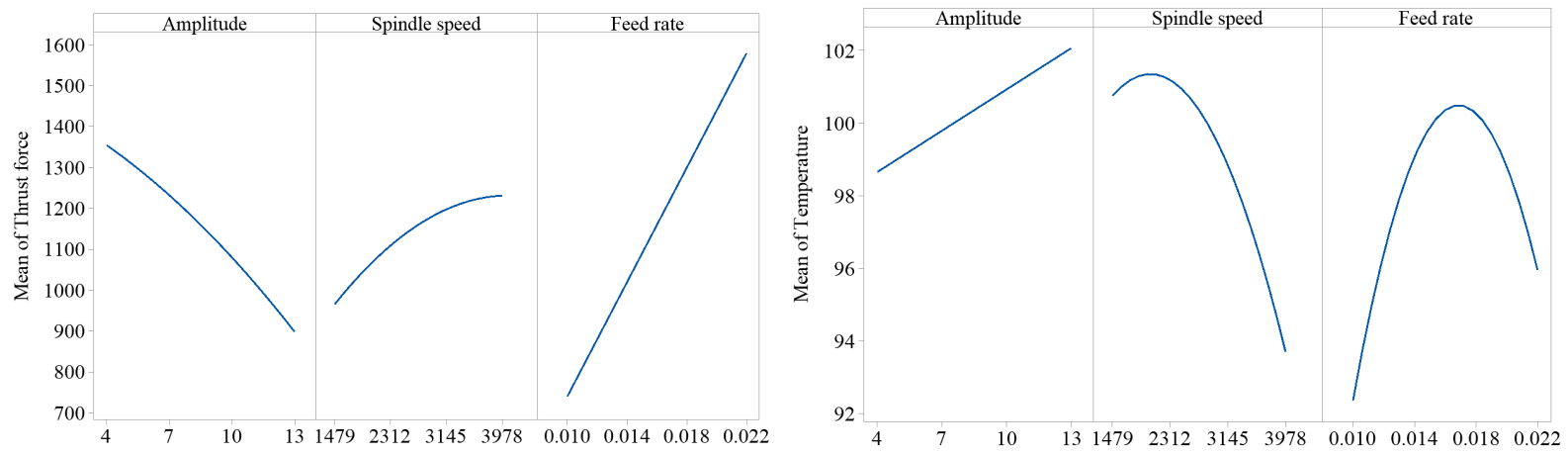

(a)

(b)
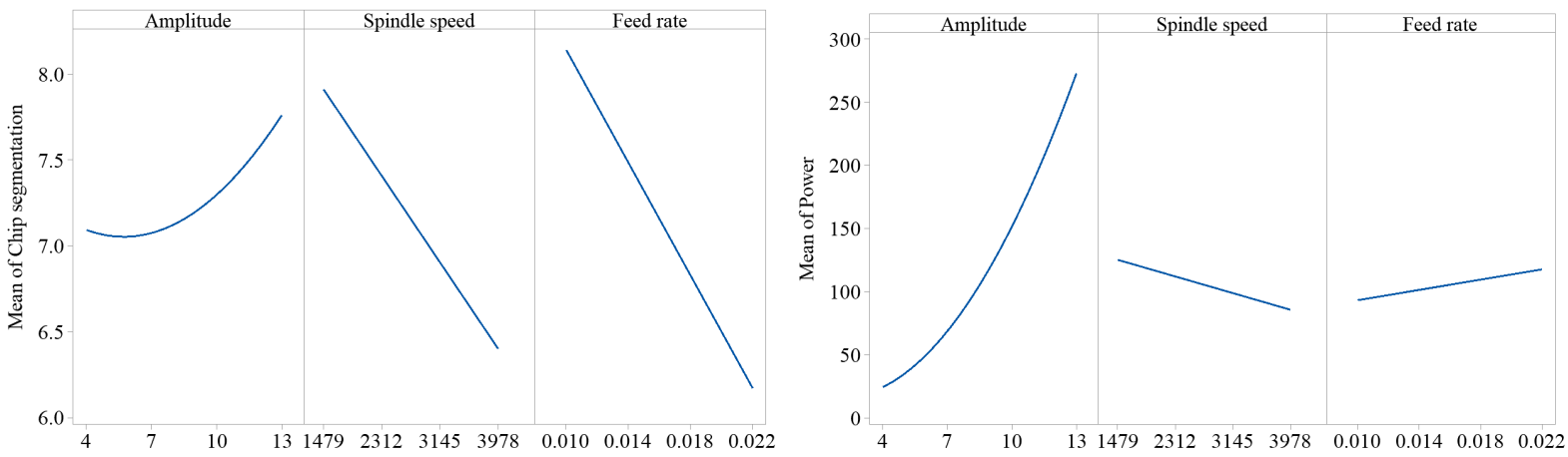

(c)

(d)

Figure 10. The Main Effects Plots for a) Thrust Force; b) Temperature; and c) Chips segmentation; d) Power

As seen in Figure 10a, the main effects plots of thrust force indicate that an increase in spindle speed and feed rate enhances the thrust force, while increasing amplitude reduces the thrust force. Note that the higher slope of feed rate graph indicates the more the effect of this parameter on thrust force compared to other drilling parameters. In Figure 10b, the spindle speed had the most effect on the temperature and increasing this parameter decreased the average temperature. As seen in Figure 10c, the feed rate had the most effect on the chip segmentation and increasing this parameter decreased the number of the chips generated. The same reduction 
can be seen in the chip segmentation by increasing the spindle speed, but the effect was less. Conversely, amplitude had a positive effect on the chip segmentation as increased chip segmentation increased and provided smaller chips. Finally, as shown in Figure 10d, amplitude had the most effect on the average power and increasing this parameter increased the average power, which was predictable before the analysis. Increasing spindle speed had an opposite effect on the power consumed and reduced the power, while increasing the feed rate increased the power.

The interactions and contour plots for thrust force, temperature, chips segmentation and power are shown in Figure 11, Figure 12, Figure 13, and Figure 14, respectively. Note that the interaction plots with gray background represent a term which is not significant.

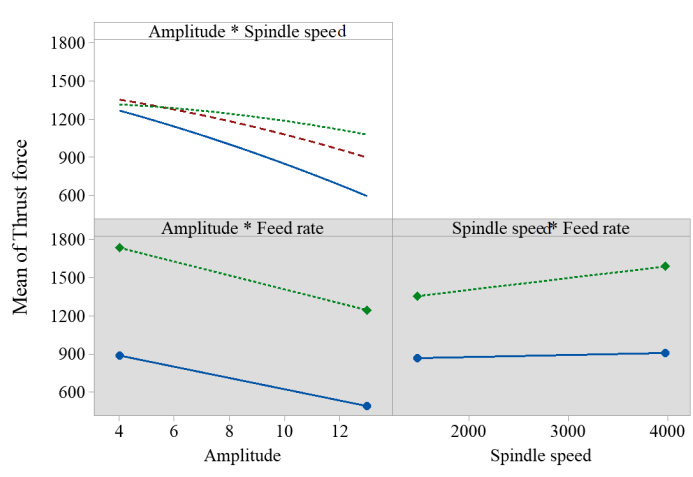

(a)

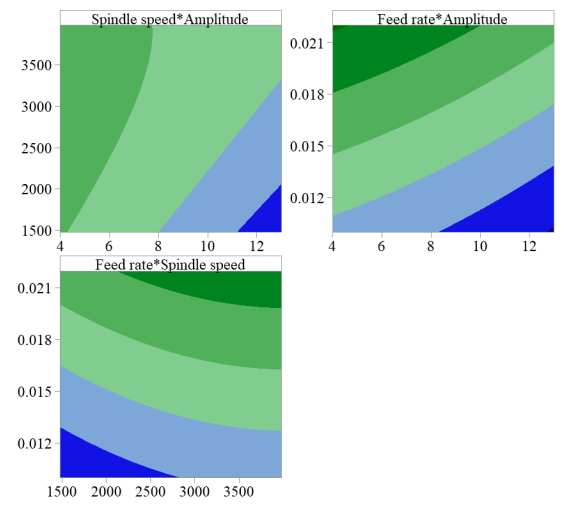

(b)

Figure 11. Thrust Force a) Interaction Plots; b) Contour Plots

From the top left plot of Figure 11a, it can be clearly seen that at low spindle speed (1479 RPM), the effect of increasing amplitude on the reduction of thrust force is greater. The contour plots shown in Figure 11b present the range of thrust force at each of the two drilling parameters, holding the third parameter. Note that the hold value is the mid-point of the minimum and maximum of the parameter. Based on these results, to minimize the thrust force, low feed rate, low spindle speed and high amplitude should be used. 


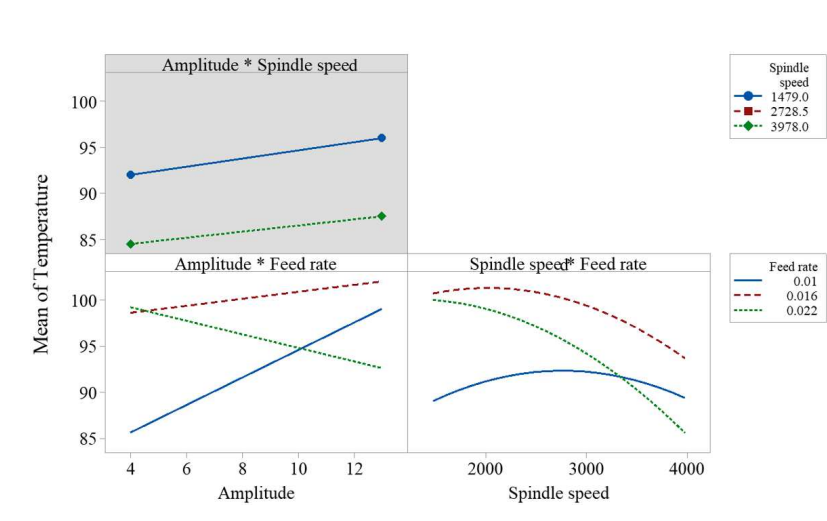

(a)

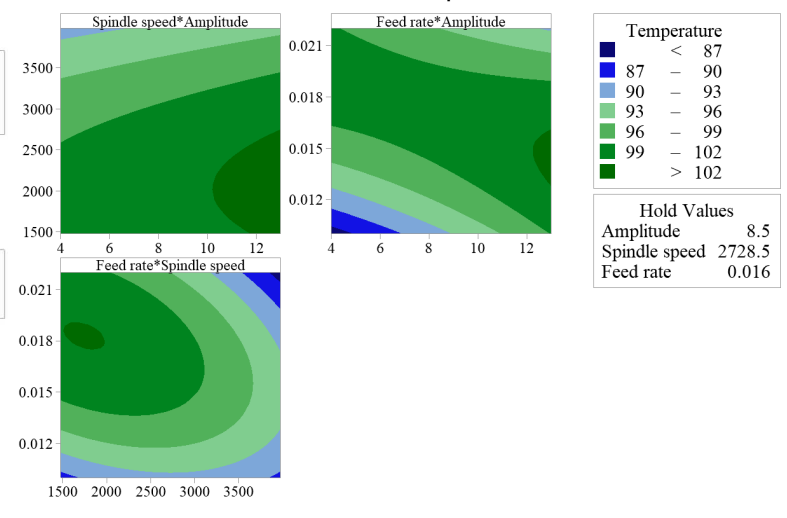

(b)

Figure 12. Temperature a) Interaction Plots; b) Contour Plots

As mentioned earlier, the interaction of amplitude and feed rate, as well as the interaction of spindle speed and feed rate, were significant. From the bottom left plot of Figure 12a, it can be concluded that the effect of amplitude on the increase of temperature is greater at a low feed rate (i.e., 0.01 IPR), while at high feed rate (i.e., 0.022 IPR), increasing amplitude reduced the temperature. These results show the importance of the interaction plots and state that to study the effect of ultrasonic vibration on generated heat, the interaction of amplitude and feed rate should be considered instead of just focusing on vibration amplitude. This finding provides pertinent additional information to better qualify the contradictory statements on whether ultrasonic vibrations increase (Pujana et al. (2009)) or does not change (Alam et al. (2015)) the generated heat during UAD. In the bottom right plot of Figure 12a, the effect of increasing spindle speed on temperature at different feed rates is provided. From this figure, it can be concluded that in drilling with a low feed rate, increasing the spindle speed had no major effect on temperature, while increasing spindle speed at high feed rate (i.e., 0.022 IPR) can cause a significant reduction of the generated heat. Based on the contour plots shown in Figure 12b, to minimize drill temperature, either low feed rate, low spindle speed and low amplitude, or high feed rate, high spindle speed and high amplitude should be used. 


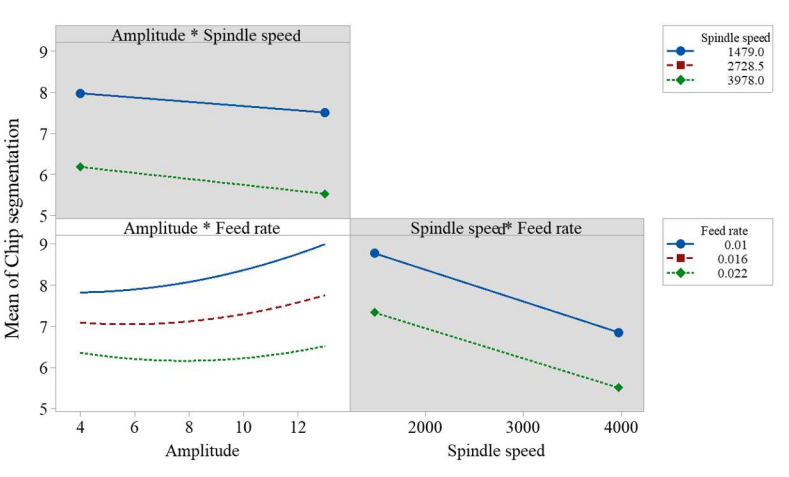

(a)

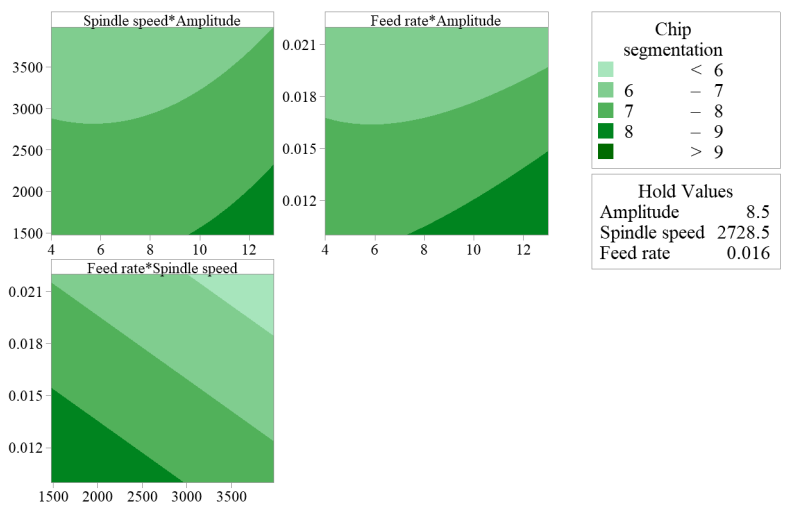

(b)

Figure 13. Chip Segmentation a) Interaction Plots; b) Contour Plots

As shown in the bottom left plot of Figure 13a, while increasing amplitude has positive effect on chip segmentation at lower feed rates (e.g., 0.01 IPR), it has no major effect on chip segmentation when high feed rate (i.e., 0.022 IPR) is being used. Based on the contour plots shown in Figure 13b, to maximize the chip segmentation, low feed rate, low spindle speed and high amplitude should be used.

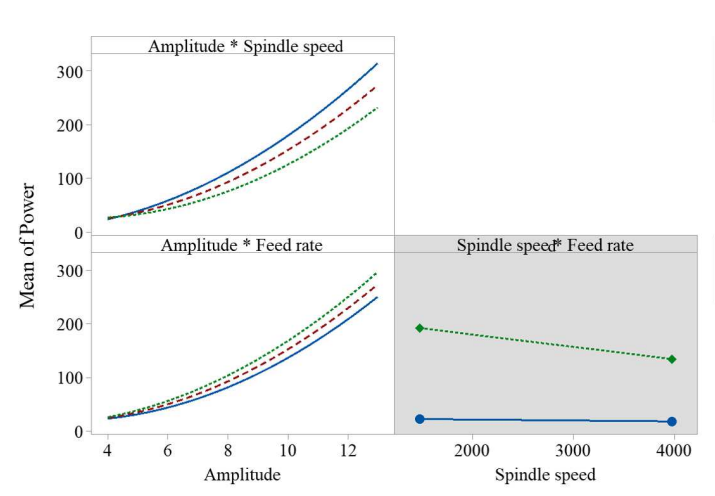

(a)
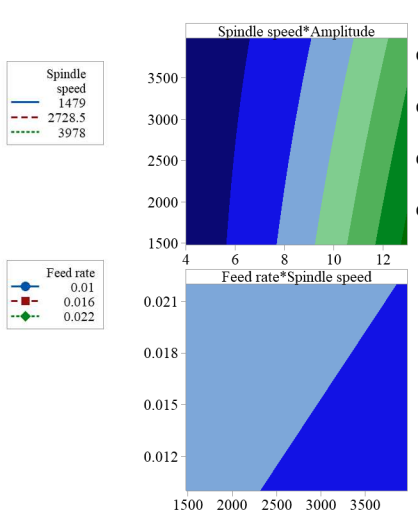
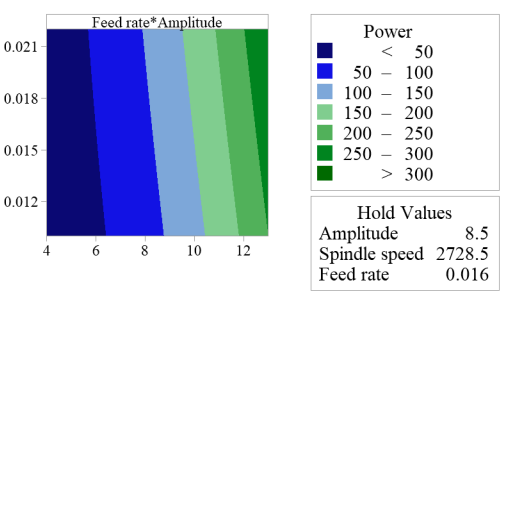

(b)

Figure 14. Consumed Power a) Interaction Plots; b) Contour Plots

For consumed power, the interaction of amplitude and spindle speed is shown in the top left plot of Figure 14a which shows that the effect of amplitude on the increase of power was greater at low spindle speed (1479 RPM), while the bottom left plot of Figure 14a indicates that the effect of amplitude on the increase of power was greater at high feed rate (0.022 IPR). By considering the bottom plot of Figure 14b, the dominant effect of amplitude on power can be clearly seen, and it can be concluded that holding amplitude (i.e., $8.5 \mu \mathrm{m}$ ), using high spindle 
speed, and low feed rate are recommended to reduce consumed power. Note that controlling consumed power is critical, specially for applications that high power is being used and could overload the power supply.

Using the Minitab Response Optimizer tool, an analysis was conducted to determine the optimum drilling parameters that minimize thrust force, temperature, power and maximize chip segmentation. The results of this evaluation for thrust force, temperature, and chip segmentation are shown in Table 9.

Table 9. The Optimized Values of Drilling Parameters that Minimize Thrust force, Temperature, and Maximize Chip Segmentation

\begin{tabular}{ccccc}
\hline Response & $\begin{array}{c}\text { Spindle Speed } \\
(\mathrm{RPM})\end{array}$ & $\begin{array}{c}\text { Feed Rate } \\
(\mathrm{IPR})\end{array}$ & $\begin{array}{c}\text { Amplitude } \\
(\mu \mathrm{m})\end{array}$ & Predicted Value \\
\hline Thrust Force (N) & 1479 & 0.01 & 13 & 174.9 \\
Temperature $\left({ }^{\circ} \mathrm{C}\right)-$ Case 1 & 1479 & 0.01 & 4 & 82.3 \\
Temperature $\left({ }^{\circ} \mathrm{C}\right)-\mathrm{Case}^{2}$ & 3978 & 0.022 & 13 & 82.3 \\
Chip Segmentation $\left(\mathrm{Grams}^{-1}\right)$ & 1479 & 0.01 & 13 & 9.8 \\
\hline
\end{tabular}

As seen in Table 9, both minimum thrust force (i.e., 174.9 N) and maximum chip segmentation (i.e., 9.8 grams-1) can be obtained at low spindle speed (i.e., 1479-RPM), low feed rate (i.e., 0.010-IPM), and high amplitude $(13-\mu \mathrm{m})$. These results show that, by using optimized settings, the minimum thrust force happens when the smallest chip size (i.e., maximum chip segmentation) generates. These results state that, during UAD of Aluminum 6061, the multiimpact interaction between the tool and the chips is intensified by using low spindle speed, low feed rate and high amplitude. These findings are aligned with the concept of critical velocity discussed in other ultrasonic-assisted machining processes (Nategh et al. (2012)) and the concept of cutting ratio described in Li-Jiang et al. (2004) where cutting ratio is defined as the ratio of cutting time to total time. Note that low spindle speed, low feed rate and high amplitude increase idle time (i.e., the time that tool is not engaged with material). Therefore, cutting time decreases and causes more separation of tool from material which boost the intermittent cutting during the UAD process. This intermittent cutting breaks chips into smaller segments which minimizes the average value of thrust force by making chip evacuation easier.

According to Table 9, minimum drill temperature $\left(82.3^{\circ} \mathrm{C}\right)$ can be obtained at either low spindle speed (i.e., 1479 RPM), low feed rate (i.e., 0.010 IPM), and low amplitude (4 $\mu \mathrm{m})$ or at high spindle speed (i.e., 3978 RPM), high feed rate (i.e., 0.022 IPM), and high amplitude (13 $\mu \mathrm{m})$. The optimization results of consumed power are summarized in Table 10. 
Table 10. The Optimized Values of Drilling Parameters that Minimize Consumed Power

\begin{tabular}{ccccc}
\hline Case No. & $\begin{array}{c}\text { Spindle Speed } \\
(\mathrm{RPM})\end{array}$ & $\begin{array}{c}\text { Feed Rate } \\
(\mathrm{IPR})\end{array}$ & $\begin{array}{c}\text { Amplitude } \\
(\mu \mathrm{m})\end{array}$ & Predicted Value \\
\hline 1 & 1479 & 0.01 & 4 & 21.5 \\
2 & 3978 & 0.01 & 7 & 47.9 \\
3 & 3978 & 0.01 & 10 & 109.1 \\
4 & 3978 & 0.01 & 13 & 208.9 \\
\hline
\end{tabular}

As shown earlier in the bottom plot of Figure 14b, consumed power was significantly governed by amplitude, therefore, in Table 10, the optimized values of drilling parameters that minimize the consumed power were obtained at each amplitude, separately. The results of this analysis showed that at $4-\mu \mathrm{m}$ amplitude, minimum consumed power $(21.5 \mathrm{~W})$ can be obtained using low spindle speed (i.e., 1479 RPM) and low feed rate (i.e., 0.010 IPM), while at higher amplitudes (i.e., 7-11 $\mu \mathrm{m}$ ), using high spindle speed (i.e., 3978 RPM) and low feed rate (i.e., 0.010 IPM) would minimize the consumed power.

Equation 3, 4, 5, and 6 were formed as regression models of thrust force, temperature, chip segmentation and power in the UAD of Aluminum 6061.

$$
\begin{aligned}
& F_{z}=215.1-75.4 A+0.1579 N+69994 F-1.651 A^{2}-0.000040 N^{2}+0.01936 A N \\
& T=-5.8+3.352 A+0.01602 N+8744 F-0.000002 N^{2}-172440 F^{2}-185.8 A F-0.494 N F \\
& C S_{i}=10.498-0.003 A-0.000605 N-84.8 F+0.01336 A^{2}-9.36 A F \\
& P=1.9-4.7 A+0.01671 N-1390 F+2.136 A^{2}-0.003827 A N+402.9 A F
\end{aligned}
$$

where $\mathrm{A}$ is amplitude in $\mu \mathrm{m}, \mathrm{N}$ is spindle speed in RPM, and $\mathrm{F}$ is feed rate in IPR. $\mathrm{R}^{2}$ coefficient is being used to check the goodness of fit of the regression model and measures how much variability in the observed response can be explained by the model. Note that while $\mathrm{R}^{2}$ close to 1 is desirable and a higher $\mathrm{R}^{2}$ is an indicator of a better goodness of fit.

The values of $\mathrm{R}^{2}$ for thrust force, temperature, chip segmentation and power are $99.7 \%$, $80.6 \%, 92 \%$ and $99.4 \%$, respectively. These $\mathrm{R}^{2}$ values indicate that the regression models fit well the observed data.

Out-of-sample testing or cross-validation method is a technique used to check the accuracy of the developed models (Geisser 1993). In this method, the original samples are divided into two data sets: training and testing sets. The training set, which was the $85 \%$ of the original data, was used to create the model and the testing set (i.e., the remaining $15 \%$ of the 
original data), was applied to validate the model. The results of out-of-sample testing of all models are provided in Table 11.

Table 11. Values of Experimental and Predicted Thrust Force, Temperature, Chips Segmentation and Consumed Power in the UAD of Aluminum 6061

\begin{tabular}{|c|c|c|c|c|c|c|c|c|c|c|c|c|}
\hline & \multicolumn{3}{|c|}{ Thrust Force } & \multicolumn{3}{|c|}{ Temperature } & \multicolumn{3}{|c|}{ Chips Segmentation } & \multicolumn{3}{|c|}{ Consumed Power } \\
\hline$\stackrel{\overrightarrow{8}}{\oplus}$ & 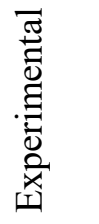 & 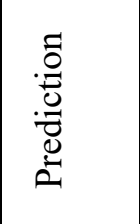 & 苛 & 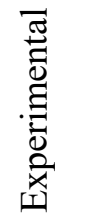 & 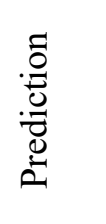 & $\stackrel{t}{t}$ & 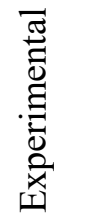 & 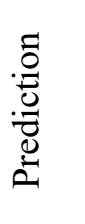 & $\stackrel{\check{0}}{t=}$ & 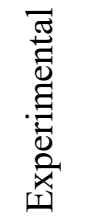 & 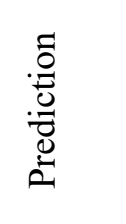 & 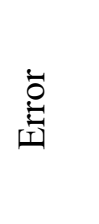 \\
\hline & $\mathrm{N}$ & $\mathrm{N}$ & $\%$ & ${ }^{\circ} \mathrm{C}$ & ${ }^{\circ} \mathrm{C}$ & $\%$ & $\mathrm{Gr}^{-1}$ & $\mathrm{Gr}^{-1}$ & $\%$ & $\mathrm{~W}$ & $\mathrm{~W}$ & $\%$ \\
\hline 1 & 1532 & 1495.67 & 2.43 & 87.00 & 98.30 & 12.99 & 6.515 & 6.60 & 1.25 & 22.70 & 25.64 & 12.94 \\
\hline 2 & 1204 & 1215.70 & 0.97 & 95.00 & 94.58 & 0.44 & 6.910 & 7.09 & 2.54 & 22.45 & 24.75 & 10.25 \\
\hline 3 & 1569 & 1549.81 & 1.24 & 97.00 & 92.09 & 5.33 & 6.015 & 5.98 & 0.65 & 150.65 & 158.75 & 5.38 \\
\hline 4 & 1052 & 1053.13 & 0.11 & 97.50 & 98.36 & 0.89 & 7.985 & 7.63 & 4.68 & 72.90 & 70.36 & 3.61 \\
\hline Ave. & & & 1.2 & & & 4.9 & & & 2.3 & & & 8 \\
\hline
\end{tabular}

As shown in Table 11, the models showed very good predictive ability. The average of the errors for thrust, temperature, chip and power models were $1.2 \%, 4.9 \%, 2.3 \%$ and $8 \%$, respectively.

\section{Conclusion}

In this research paper, RSM has been successfully used to develop mathematical models of thrust force, temperature, chip morphology and power in UAD of Aluminum 6061. The non-rotating compression collet module mounted into the MAZAK CNC turning center was used to perform the UAD trials. The experiments were performed based on a special resolution $\mathrm{V}$ design and the results were analyzed. The optimized drilling parameters for thrust force, temperature, chip morphology and power were determined and followed by a cross-validation to check the adequacy of the mathematical models. The following conclusions can be drawn from present statistical modeling of surface roughness:

(1) The benefits of UAD do not necessarily occur at the same time and sometimes achieving one benefit may require sacrificing another. 
(2) Analysis of the thrust force data showed that, among the drilling parameters, feed rate had the most effect. Amplitude was the second most significant parameter and spindle speed had the least effect on thrust force. The interaction plots showed that the effect of amplitude on the reduction of thrust force was greater at low spindle speeds.

(3) Analysis of the temperature data indicated that, while, at a low feed rate, the effect of increasing amplitude on the increase of temperature is greater, at a high feed rate, increasing amplitude reduced the drill tip temperature. Note that at low feed rate, increasing the spindle speed had no major effect on temperature, while increasing spindle speed at high feed rate decreases the temperature, significantly.

(4) Similar to thrust force, chip size was mostly affected by feed rate. Then spindle speed and feed rate were the most significant parameters effecting both thrust force and chip size. This finding shows the direct relationship that exists between thrust force reduction and generation of smaller chips due to the intermittent nature of UAD of Aluminum 6061 specially at low spindle speed, low feed rate, and high amplitude.

(5) The optimized drilling parameters were found for each response, and the results suggest that, minimum thrust force and smaller chips can be obtained at low spindle speed (i.e., 1479 RPM), low feed rate (i.e., 0.01 IPR) and high amplitude (i.e., $13 \mu \mathrm{m}$ ), while minimum drill temperature can be obtained at either low spindle speed (i.e., 1479 RPM), low feed rate (i.e., 0.01 IPR) and low amplitude (i.e., $4 \mu \mathrm{m}$ ) or high spindle speed (i.e., 3978 RPM), high feed rate (i.e., 0.022 IPR) and high amplitude (i.e., $13 \mu \mathrm{m}$ ). For consumed power, at $4-\mu \mathrm{m}$ amplitude, minimum consumed power $(21.5 \mathrm{~W})$ can be obtained using low spindle speed (i.e., 1479 RPM) and low feed rate (i.e., 0.010 IPM), while at higher amplitudes (i.e., 7-11 $\mu \mathrm{m}$ ), using high spindle speed (i.e., 3978 RPM) and low feed rate (i.e., 0.010 IPM) would minimize the consumed power.

(6) Out-of-sample testing method which was used to confirm the validity of the models showed that the models can be effectively used to predict thrust force, temperature, chip index and power in UAD of aluminum 6061 within the limits of factors studied.

\section{Acknowledgment}

The authors would like to thank Edison Welding Institute (EWI) for providing the funding and equipment for this investigation. 


\section{Declarations}

\section{Funding}

This research was funded by EWI.

\section{Conflicts of Interest}

The author declares that he has no known competing financial interests or personal relationships that could have appeared to influence the work reported in this paper.

\section{Availability of Data and Material}

Not applicable

\section{Code Availability}

Not applicable

\section{References}

Alam, K., Hassan, E., \& Bahadur, I. (2015). "Experimental Measurements of Temperatures in Ultrasonically Assisted Drilling of Cortical Bone.” Biotechnology \& Biotechnological Equipment, (29)4, 753-757.

Chu, N., Nguyen, V., \& Ngo, Q. (2020). Machinability enhancements of ultrasonic-assisted deep drilling of aluminum alloys. Machining Science and Technology, 24(1), 112-135. doi:10.1080/10910344.2019.1636267

Diamond, W. J. (1981). Practical experiment designs for engineers and scientists. Belmont, Calif: Lifetime Learning Publications.

Geisser, S. (1993). Predictive Inference: An Introduction. New York: Chapman \& Hall.

Kennametal. (2013). Innovations Master Catalogue-Cutting Tools: G21-G26.

Li-Jiang, W., Wang, X., \& Hai-Fang, Z. (2004). Effect of the cutting ratio on cutting forces and the drill life in vibration drilling. The International Journal of Advanced Manufacturing Technology, 24(11-12), 865-872. http://dx.doi.org/10.1007/s00170-003-1803-y 
Li, X., Dong, Z., Kang, R., Wang, Y., Liu, J., \& Zhang, Y. (2016). Comparison of thrust force in ultrasonic assisted drilling and conventional drilling of aluminum alloy. Materials Science Forum, 861, 38-43. doi:10.4028/www.scientific.net/MSF.861.38

Ma, C.X., Shamoto, E., \& Moriwaki, T. (2005). "Drilling Assisted by Ultrasonic Elliptical Vibration.” Key Engineering Materials, (291-292), 443-446.

Moghaddas, M. A. (2021)," Modeling and optimization of thrust force, torque, and surface roughness in ultrasonic-assisted drilling using surface response methodology," The International Journal of Advanced Manufacturing Technology, 20210109.

Moghaddas, M. A. and Graff, K. F. (2020), "On the effect of load on vibration amplitude in ultrasonic-assisted drilling," The International Journal of Advanced Manufacturing Technology, 1-14.

Moghaddas, M.A., Short, M.A., Wiley, N.R., Yi, A.Y., \& Graff, K.F. (2018a). "Improving Productivity in an Ultrasonic-Assisted Drilling Vertical Machining Center.” Journal of Manufacturing Science and Engineering, (140)6.

Moghaddas, M.A., Short, M.A., Wiley, N.A., Yi, A.Y., \& Graff, K.F. (2018b). "Performance of an Ultrasonic-Assisted Drilling Module.” The International Journal of Advanced Manufacturing Technology, (94), 3019-3028.

Moghaddas, M.A., Yi, A.Y., \& Graff, K.F. (2019). “Temperature Measurement in the Ultrasonic-Assisted Drilling process.” The International Journal of Advanced Manufacturing Technology. 10.1007/s00170-019-03487-7.

Nategh, M. J., Razavi, H., \& Abdullah, A. (2012). Analytical modeling and experimental investigation of ultrasonic-vibration assisted oblique turning, part I: Kinematics analysis. International Journal of Mechanical Sciences, 63(1), 1-11.

Neugebauer, R., \& Stoll, A. (2004). "Ultrasonic Application in Drilling.” Journal of Materials Processing Tech, (149)1, 633-639.

Onikura, H., Ohnishi, O., Feng J., Kanda T., \& Morita, T. (1966). “Effects of Ultrasonic Vibration on Machining Accuracy in Microdrilling." Journal of the Japan Society for Precision Engineering, (62)5, 676-680.

Pujana J, Rivero A, Celaya A, Lopez De Lacalle LN (2009) Analysis of ultrasonic-assisted drilling of Ti6Al4V. Int J Mach Tool Manu 49:500-508

Takeyama, H., \& Kato, S. (1991). “Burrless Drilling by Means of Ultrasonic Vibration.” Annals of the CIRP, (40)1, 83-86. 
Wei, L., \& Wang, D. (2019). Comparative study on drilling effect between conventional drilling and ultrasonic-assisted drilling of ti-6al-4v/al2024-t351 laminated material. The International Journal of Advanced Manufacturing Technology, 103(1-4), 141-152. doi:10.1007/s00170-019-03507-6

Wei, L., \& Wang, D. (2020). Effect of ultrasound-assisted vibration on ti-6al-4v/al2024-t351 laminated material processing with geometric tools. International Journal of Advanced Manufacturing Technology, 106(1-2), 219-232. doi:10.1007/s00170-019-04637-7 


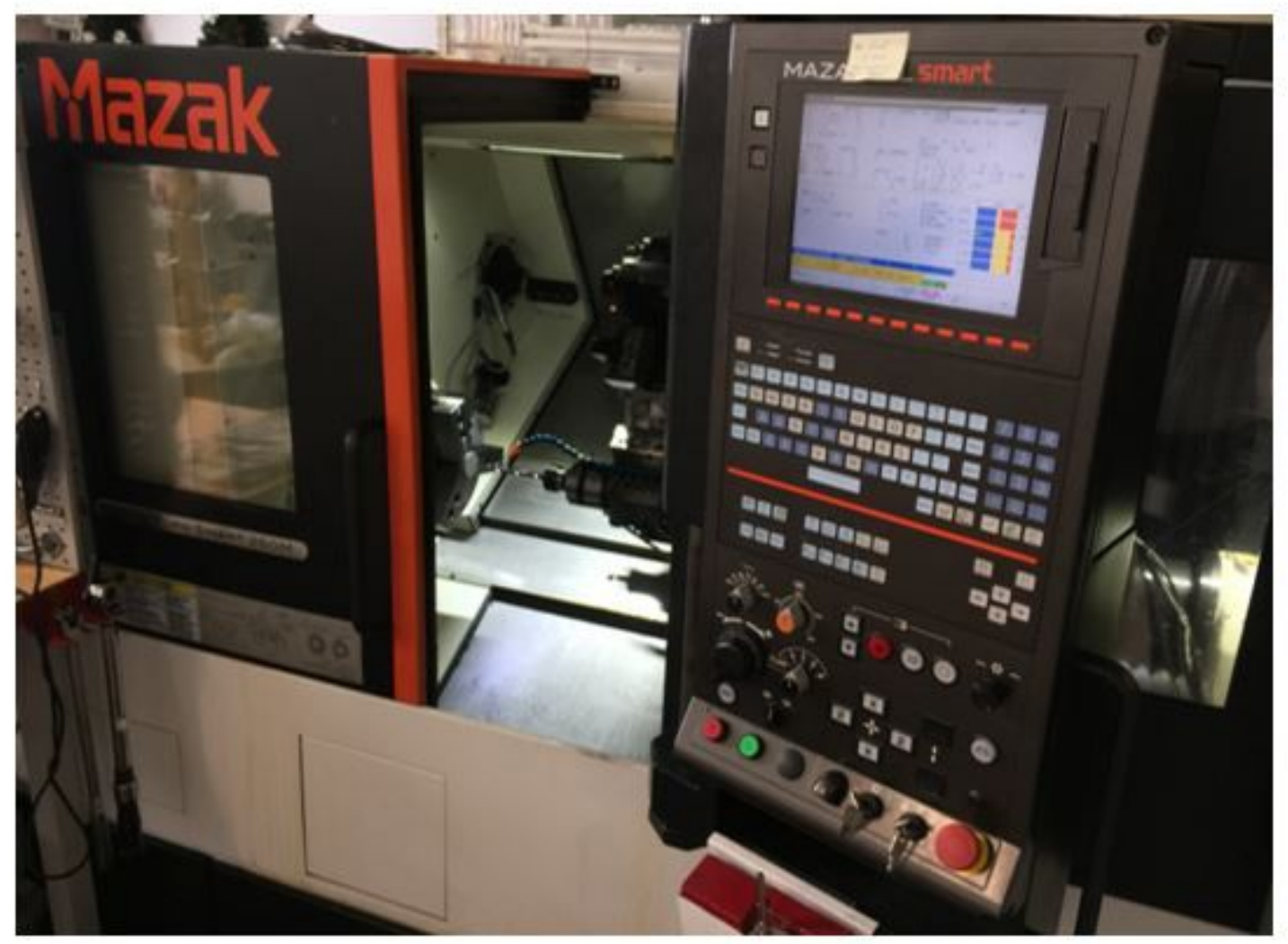

Figure 1

Experimental Setup

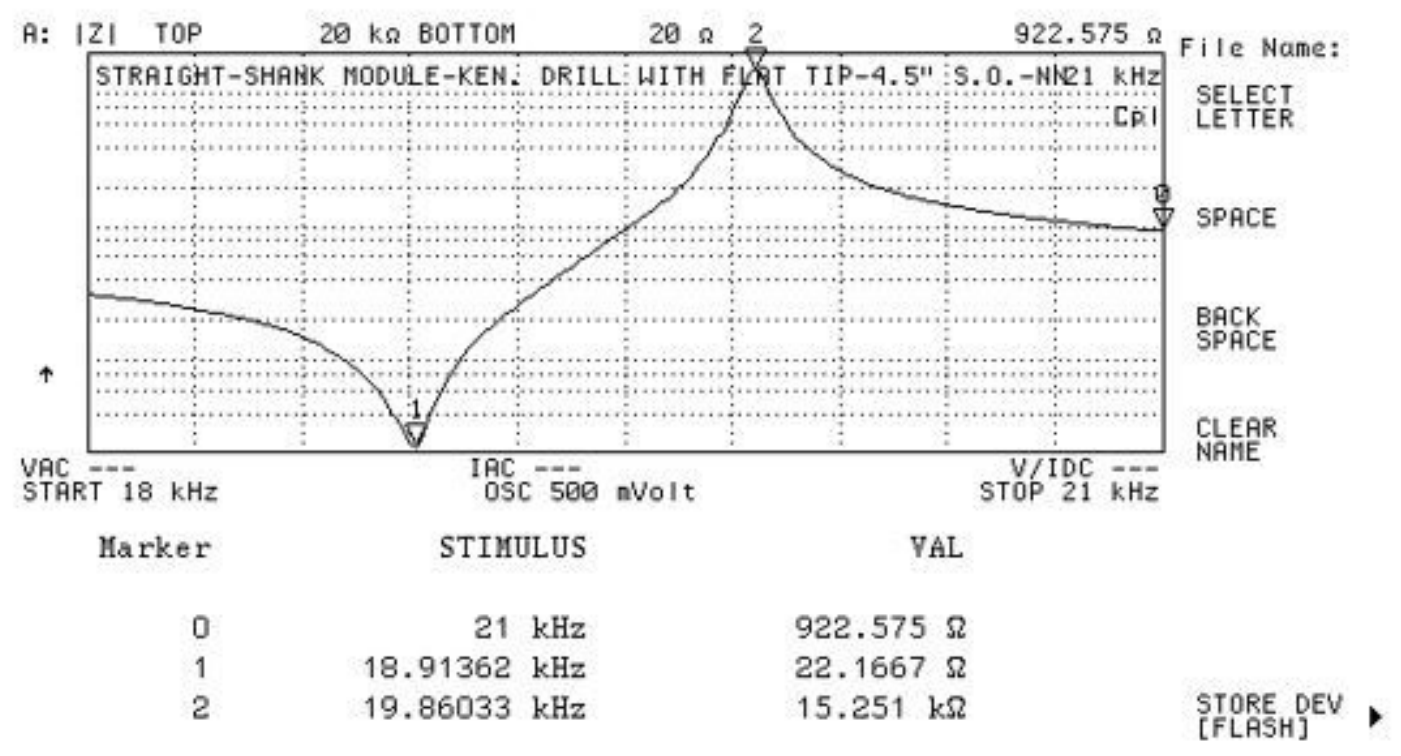

Figure 2 
Impedance Curve of the Non-Rotating Compression Collet Module

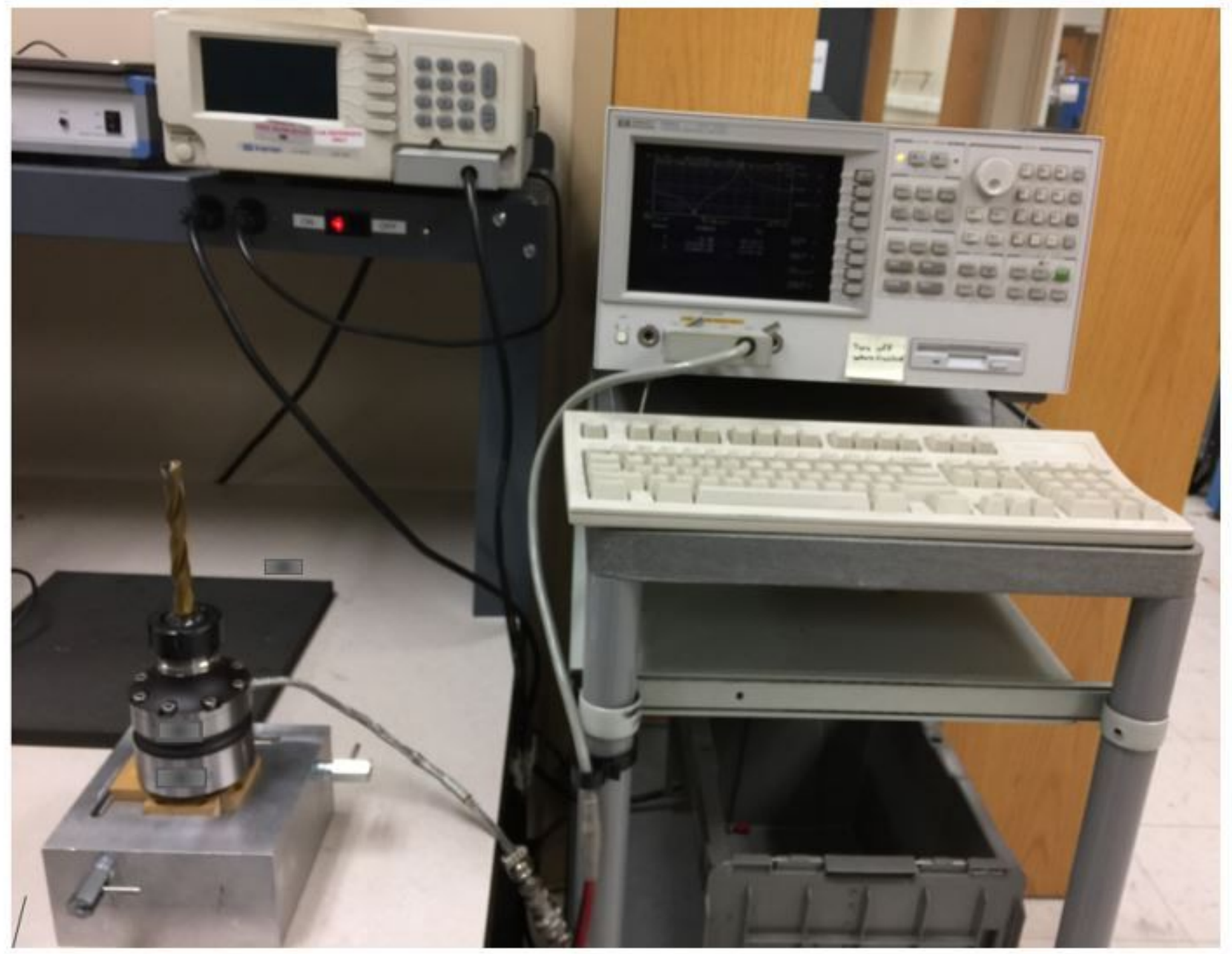

Figure 3

Hewlett Packard Impedance Analyzer to Determine the Anti-Resonant Frequency of the UAD System 

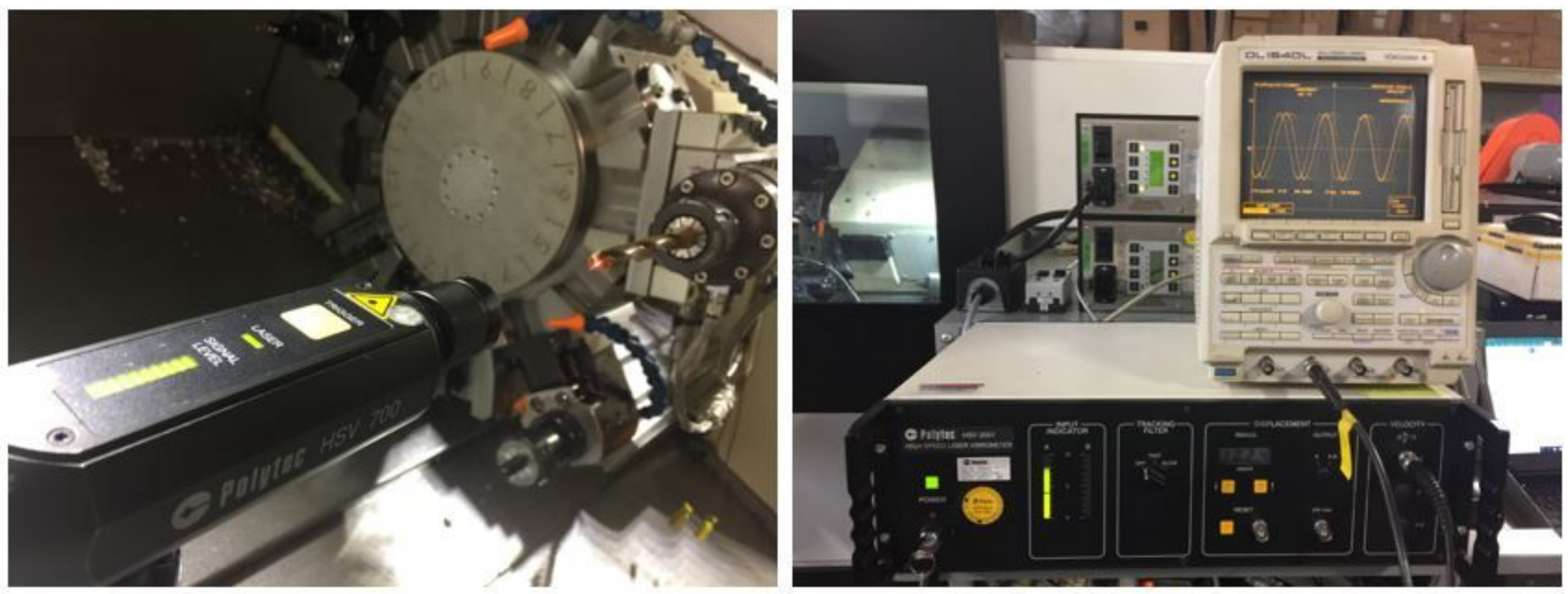

Figure 4

Setup for Amplitude Measurement on the Drill Tip

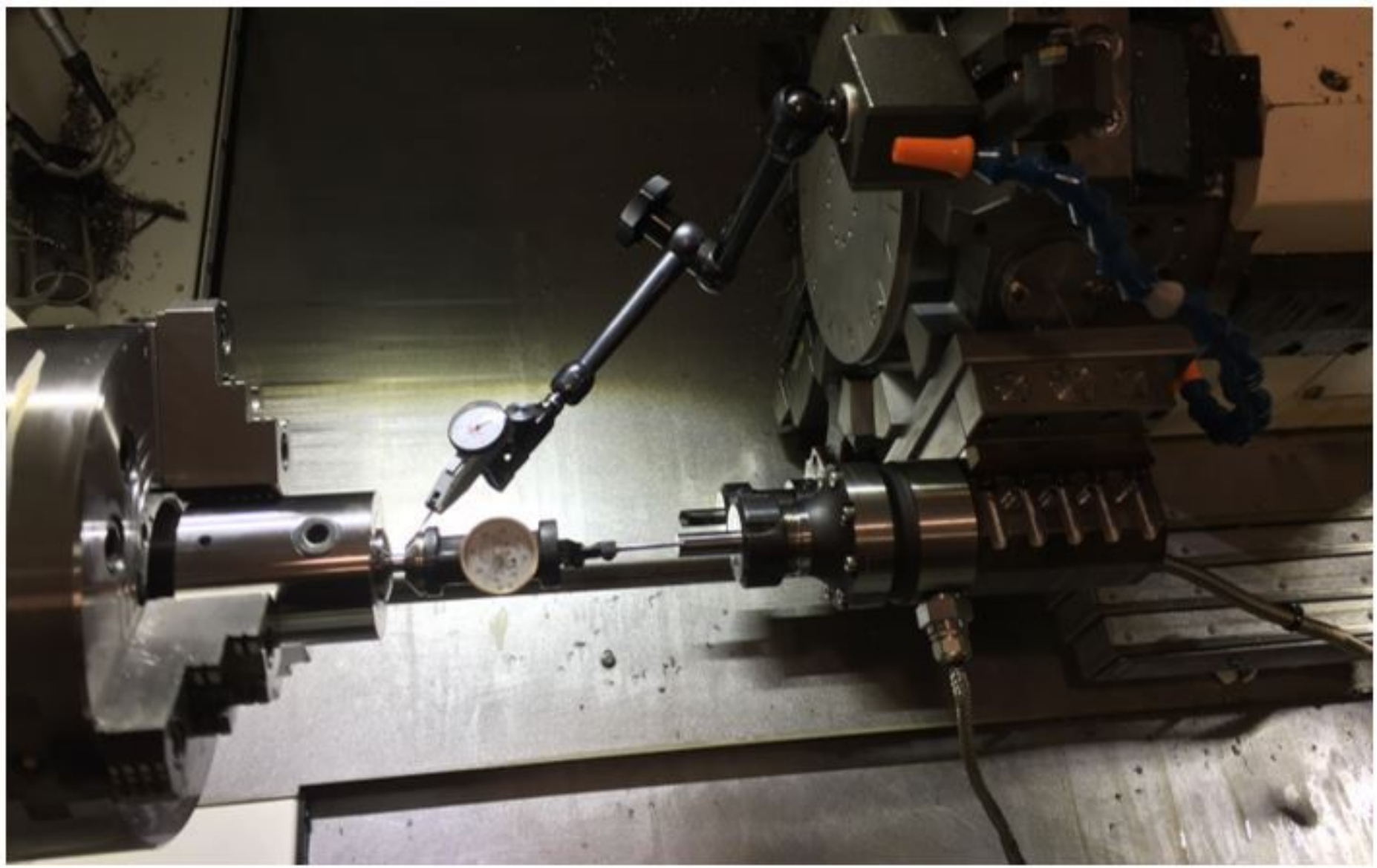

Figure 5

Setup for Aligning the Module with the Center of the Machine's Spindle 


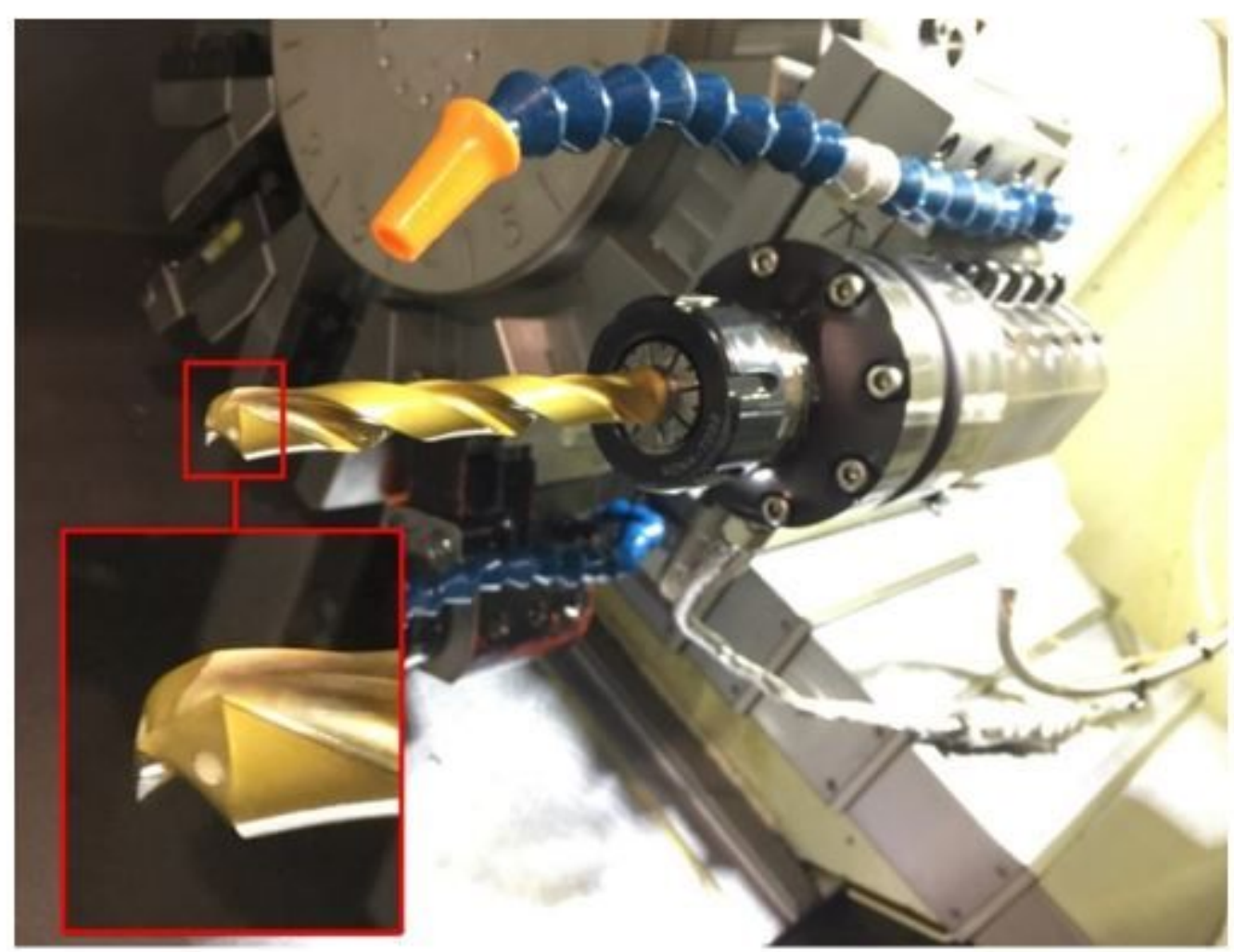

Figure 6

Thermocouples Inserted into the Cooling Channels of the Drill, then Covered with High Temperature Epoxy

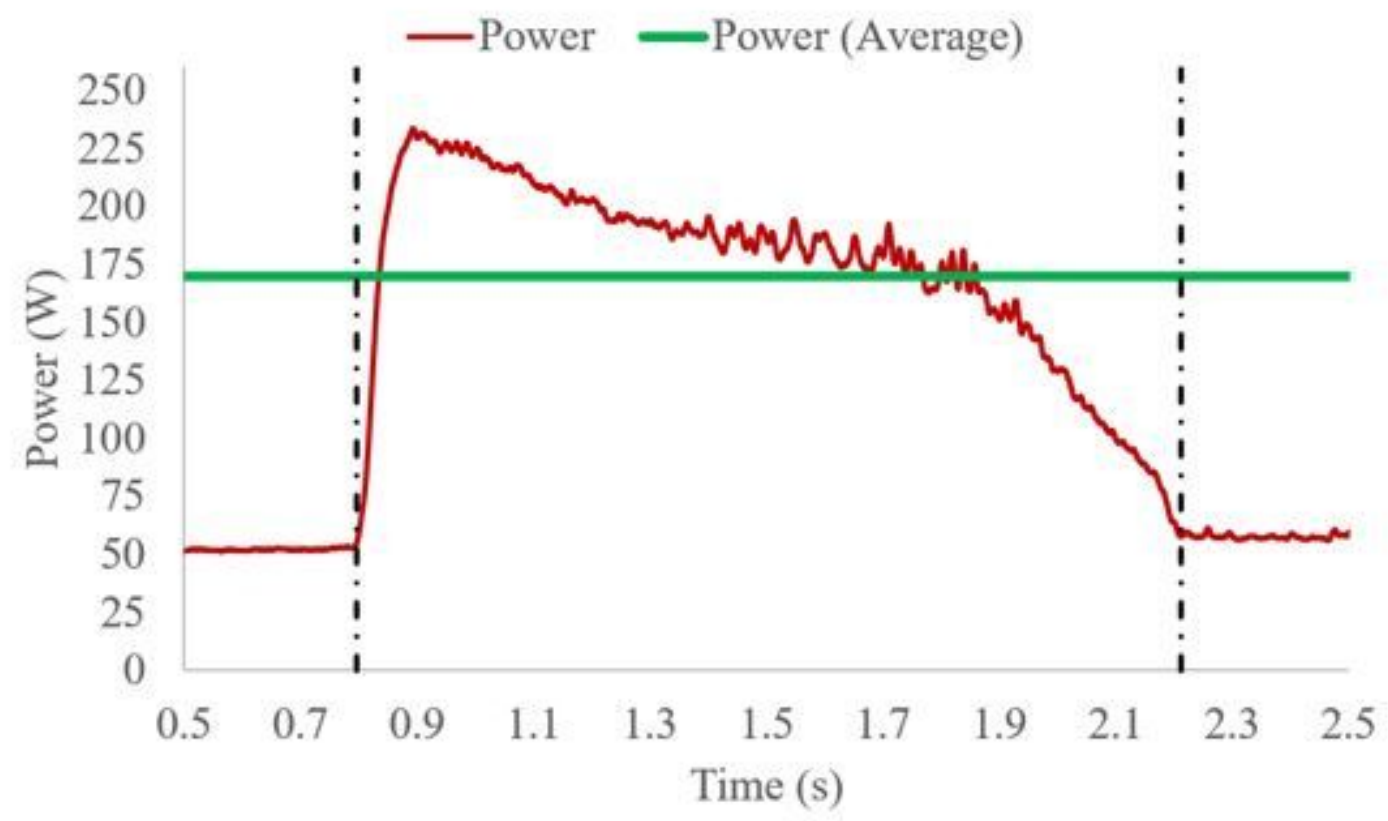

Figure 7

Representative data for the power consumed by the module during the UAD of Aluminum 6061, with 1,479 RPM, 0.014 IPR, and 10- $\mu \mathrm{m}$ amplitude 

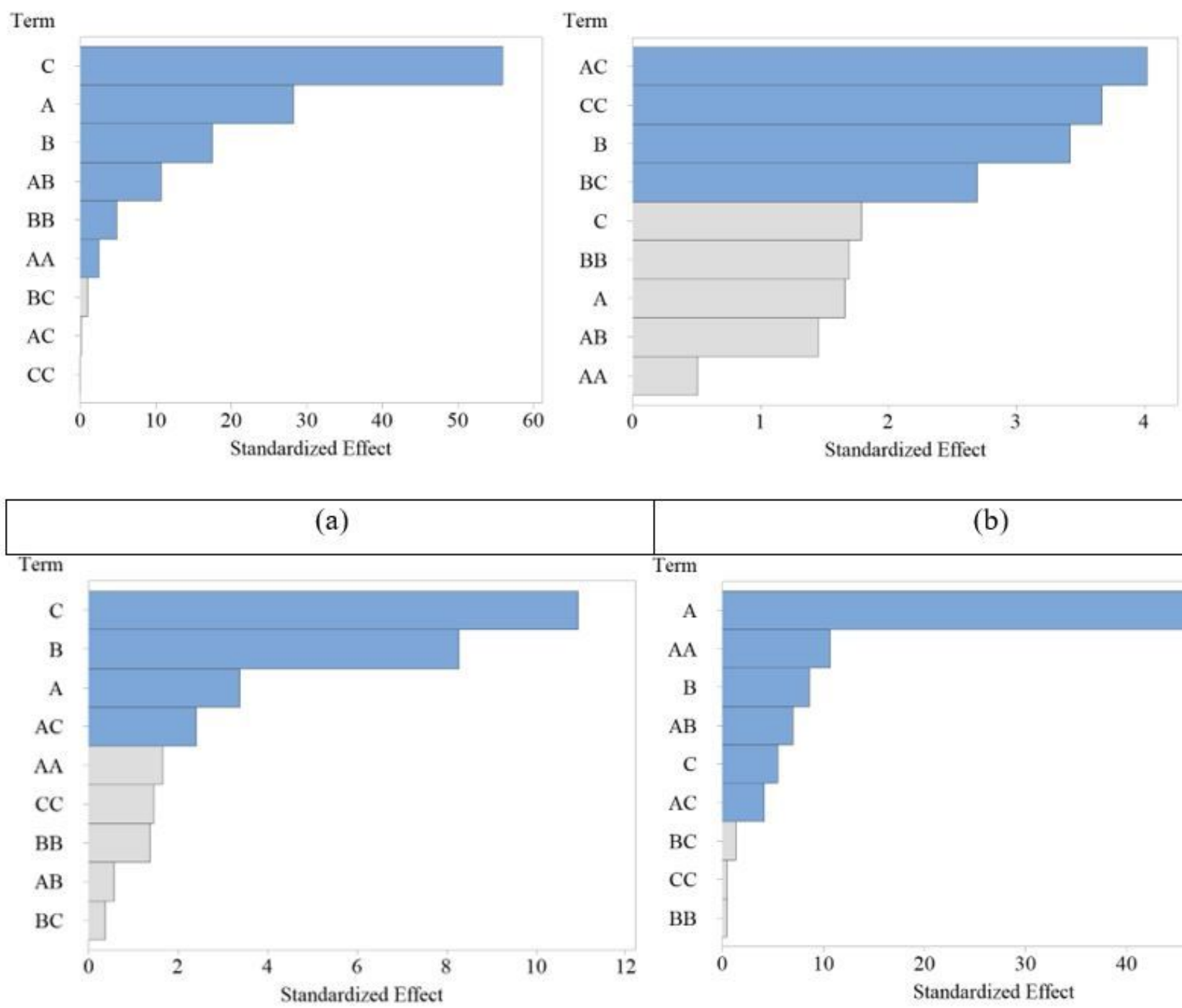

(b)

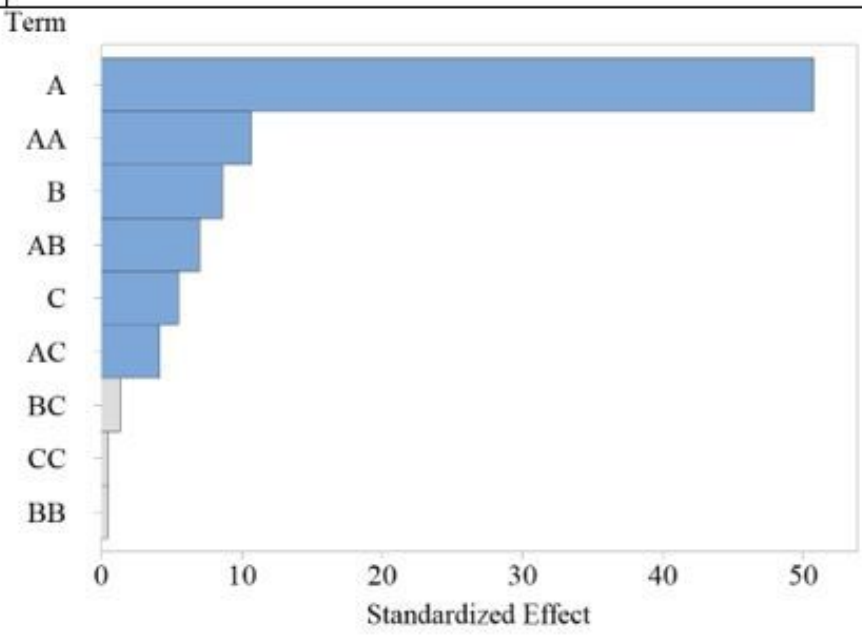

(c)

(d)

Figure 8

Pareto Chart of the Standardized Effects of a) Thrust force; b) Temperature; c) Chips segmentation; d) Power. Note: A, B and C are Amplitude, Spindle Speed and Feed Rate, Respectively. 

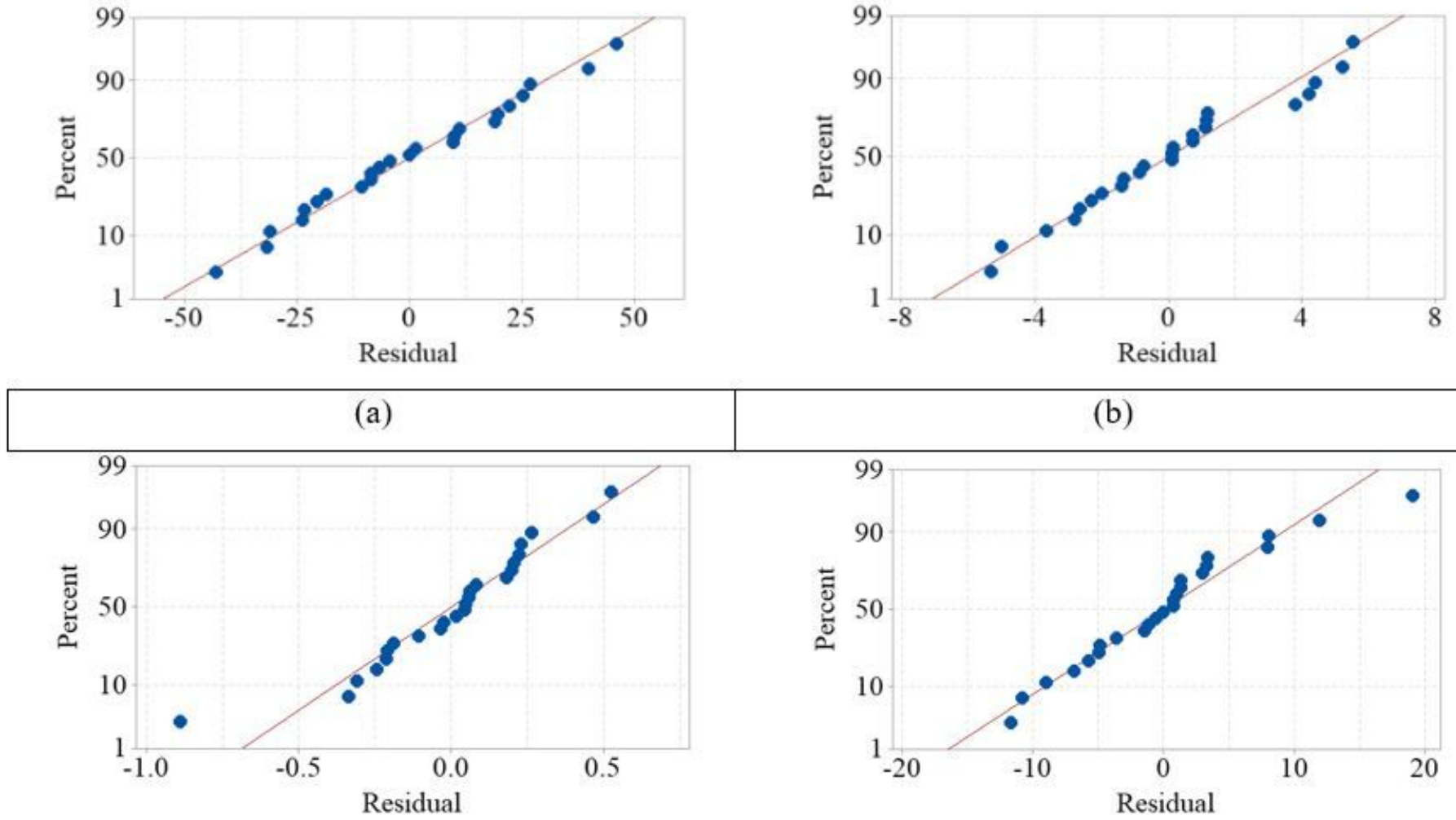

(b)

(c)

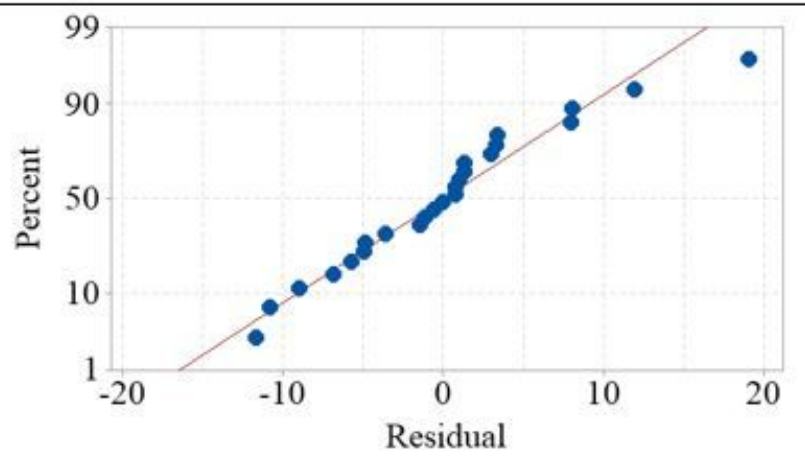

Figure 9

Residual Plots for a) Thrust Force; b) Temperature; and c) Chips segmentation; d) Power 

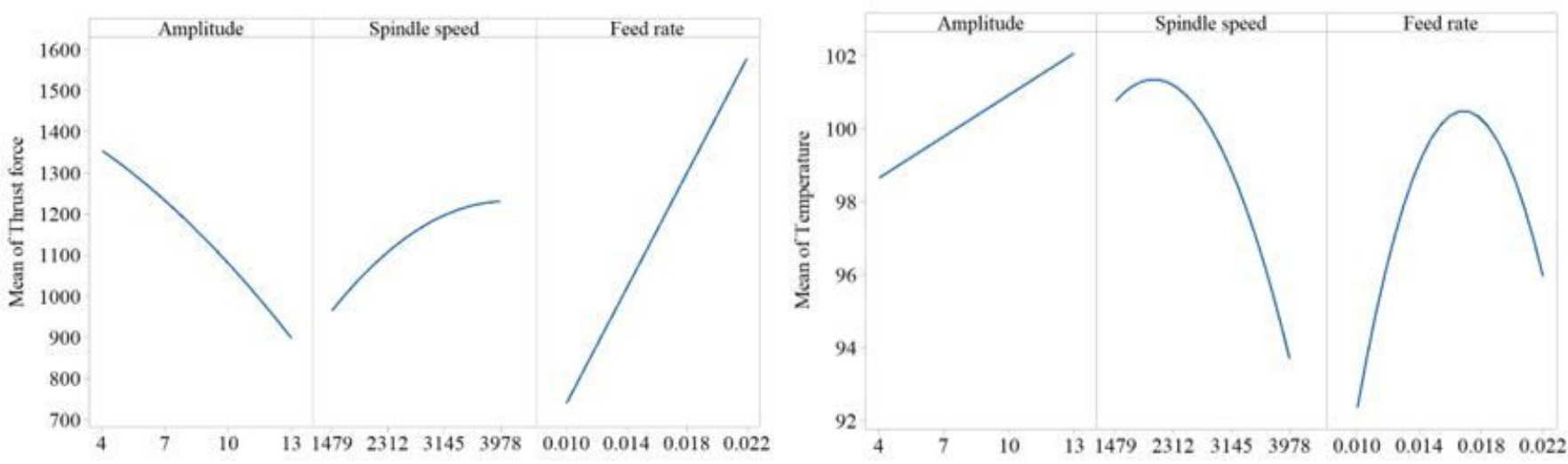

(a)

(b)
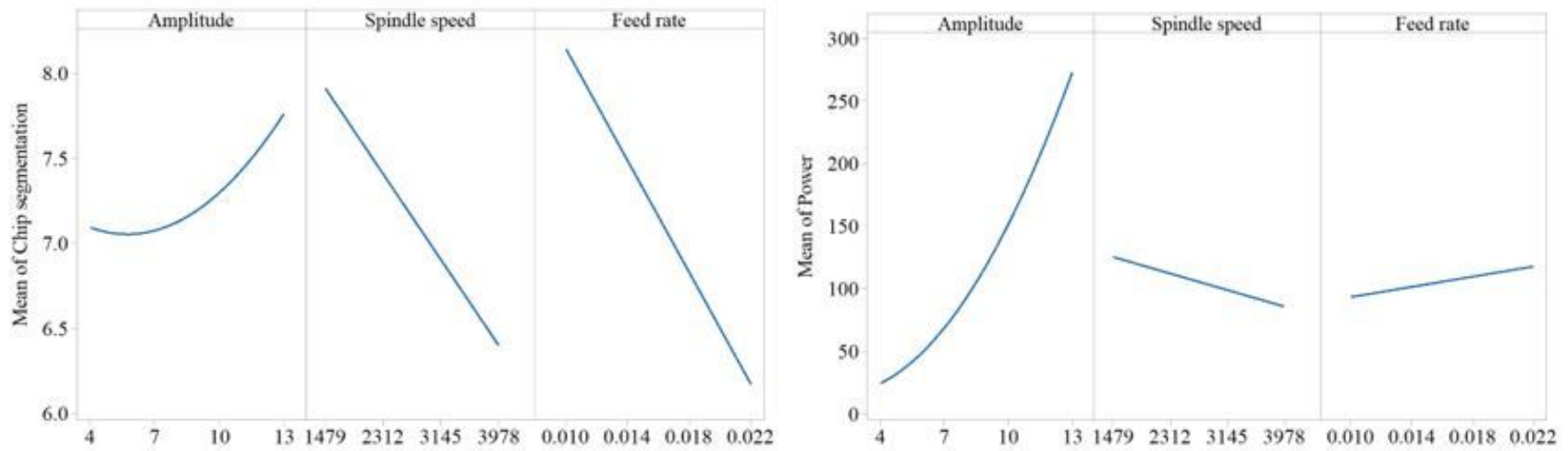

(c)

(d)

\section{Figure 10}

The Main Effects Plots for a) Thrust Force; b) Temperature; and c) Chips segmentation; d) Power
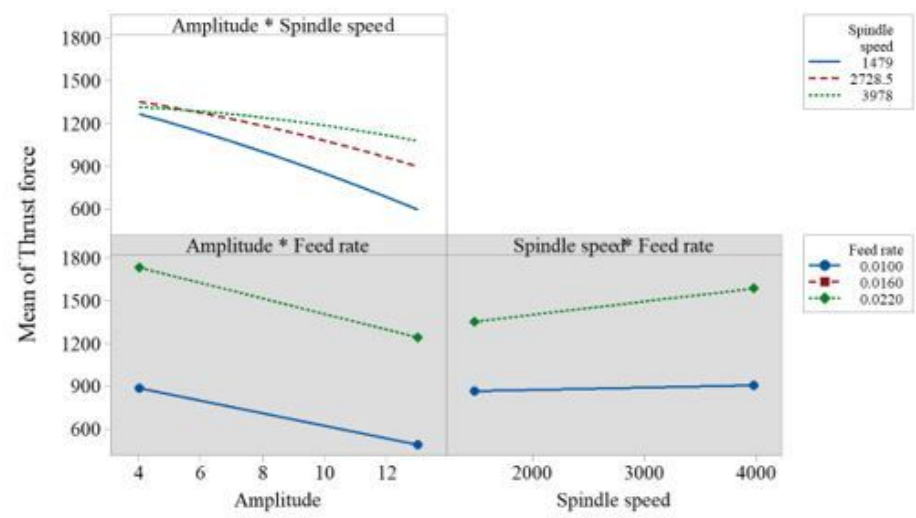

(a)
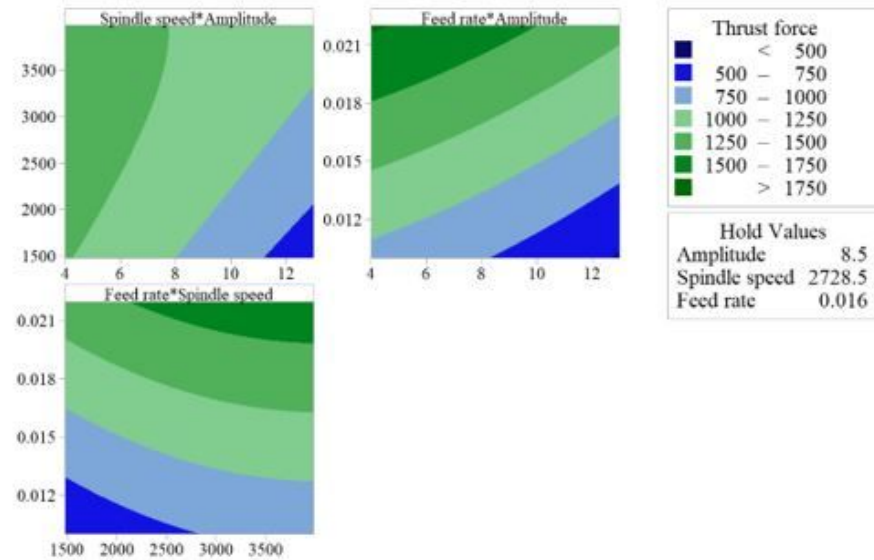

\section{Figure 11}

Thrust Force a) Interaction Plots; b) Contour Plots 

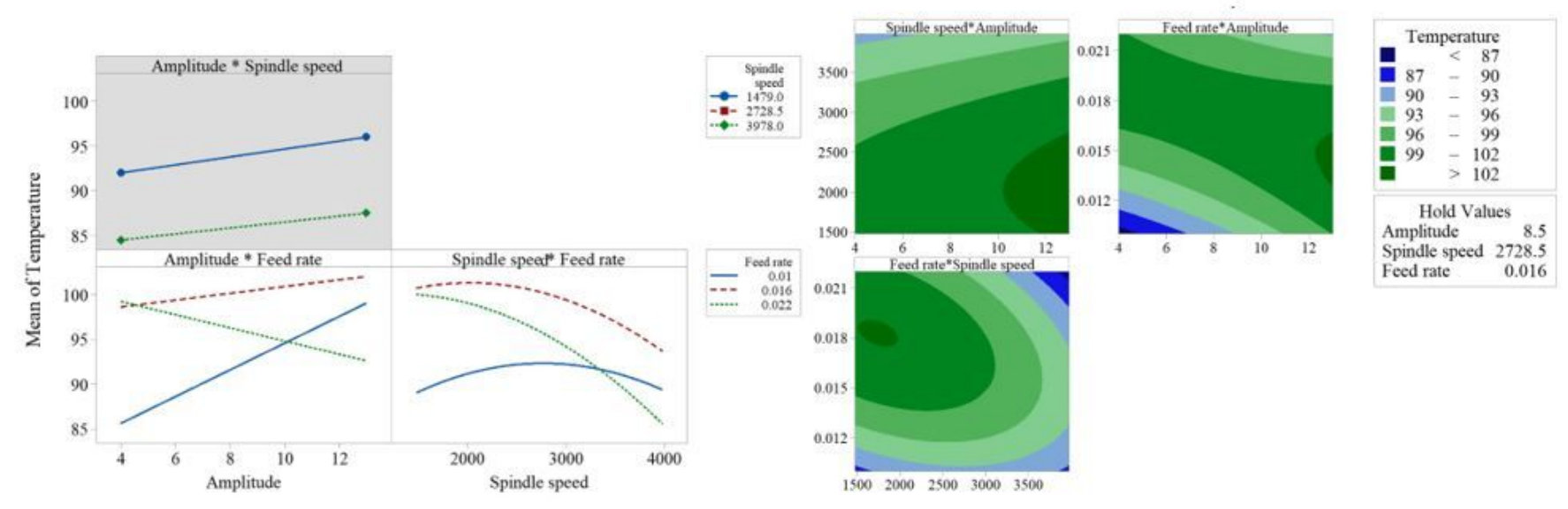

(a)

(b)

\section{Figure 12}

Temperature a) Interaction Plots; b) Contour Plots
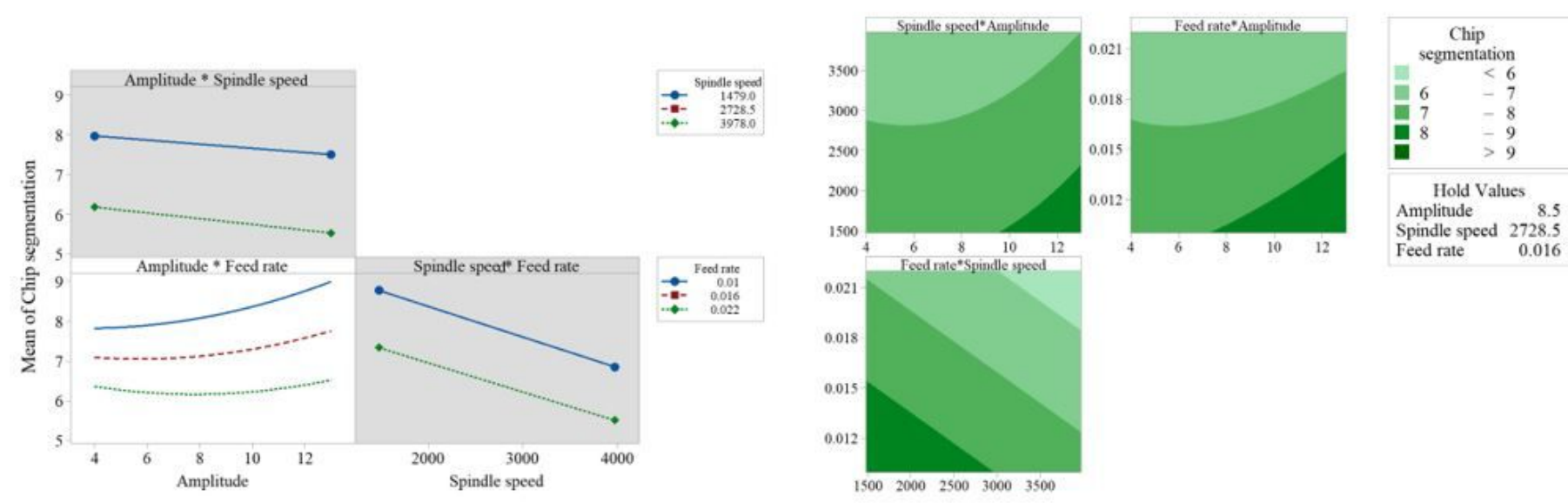

(a)

(b)

Figure 13

Chip Segmentation a) Interaction Plots; b) Contour Plots 

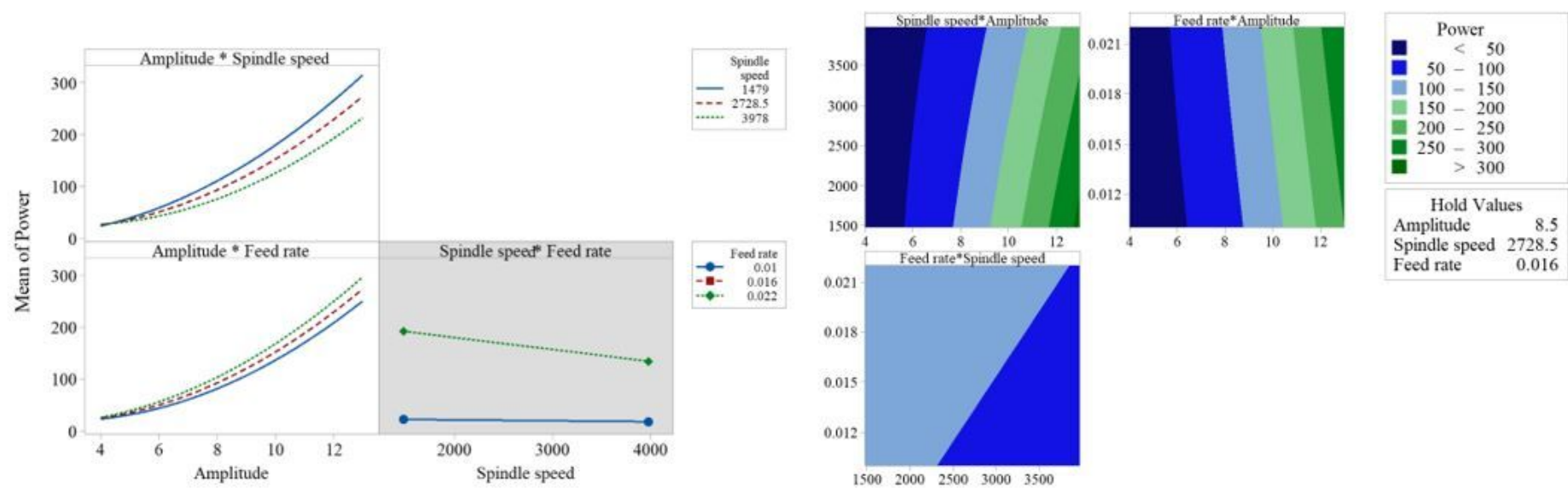

(a)

(b)

Figure 14

Consumed Power a) Interaction Plots; b) Contour Plots

\section{Supplementary Files}

This is a list of supplementary files associated with this preprint. Click to download.

- TitlePage.docx 